\title{
On the Mechanics of New-Keynesian Models*
}

\author{
Peter Rupert ${ }^{\dagger \ddagger}$ and Roman Šustek ${ }^{\S}$
}

March 31, 2016

\begin{abstract}
The monetary transmission mechanism in New-Keynesian models is put to scrutiny, focusing on the role of capital. We demonstrate that, contrary to a widely held view, the transmission mechanism does not operate through a real interest rate channel. Instead, as a first pass, inflation is determined by Fisherian principles, through current and expected future monetary policy shocks, while output is then pinned down by the New-Keynesian Phillips curve. The real rate largely only reflects consumption smoothing. In fact, declines in output and inflation are consistent with a decline, increase, or no change in the ex-ante real rate.
\end{abstract}

JEL Classification Codes: E30, E40, E50.

Keywords: New-Keynesian models, monetary transmission mechanism, real interest rate channel, capital.

\footnotetext{
${ }^{*}$ We thank James Bullard, Jesus Fernandez-Villaverde, Wouter den Haan, Marek Kapička, and Narayana Kocherlakota for valuable comments. We have also benefited from comments by seminar participants at Philladelphia Fed, UC Riverside, and the University of Kent. The financial support of the Czech Science Foundation project No. P402/12/G097 (DYME Dynamic Models in Economics) is gratefully acknowledged.

†University of California-Santa Barbara; peter.rupert@ucsb.edu.

${ }_{\ddagger}^{\ddagger}$ Corresponding author: Peter Rupert, address: Department of Economics, 2127 North Hall, Santa Barbara, CA 93106, U.S.A., tel: +1 805 893-2258, fax: +1 805 893-8830, e-mail: rupert@econ.ucsb.edu.

${ }^{\S}$ Queen Mary University of London, Centre for Macroeconomics, and CERGE-EI, a joint workplace of Charles University in Prague and the Economics Institute of the Czech Academy of Sciences; sustek19@gmail.com.
} 


\section{Introduction}

The New-Keynesian model - a dynamic stochastic general equilibrium (DSGE) model with sticky prices - has become a workhorse in the analysis of monetary policy. It has grown in popularity at tremendous speed both in academia and at central banks around the world. From a basic framework, consisting of an Euler equation, a New-Keynesian Phillips curve, and a Taylor rule, it has quickly grown into a model with many different frictions, adjustment costs, and other features. Whereas the basic framework abstracts from capital, the extended model-building on the real business cycle tradition of Kydland and Prescott (1982) and Long and Plosser (1983) - includes capital and investment as an integral part of the environment. The basic framework is typically used to discuss optimal monetary policy (e.g., Clarida, Galí, and Gertler, 1999), whereas the extended model-often referred to as a medium-scale DSGE model - is used for practical monetary policy and forecasting (Linde, Smets, and Wouters, 2015, provide a sample of central banks using such DSGE models to guide policy).

Unfortunately, in our view, widespread understanding of the internal mechanism of the New-Keynesian model has been lost along its fast track to popularity. In this respect, the existing literature offers limited help. Textbooks covering the New-Keynesian model (such as Walsh, 2010; Galí, 2015) stop at the basic framework and proceed with a discussion of optimal monetary policy, while research based on the medium-scale DSGE models (represented by, e.g., Christiano, Eichenbaum, and Evans, 2005; Smets and Wouters, 2007) starts straight away with the full-blown version. Researchers outside of this field, as well as graduate students, are left on their own to connect the dots, when moving from the first to the second strand of the literature. ${ }^{1}$

\footnotetext{
${ }^{1}$ McCandless (2008) comes closest to bridging this gap, but his treatment of New-Keynesian models is carried out in the context of a model with money and a monetary policy rule formulated as a money growth rule, whereas most of the New-Keynesian literature follows Woodford (2003) by abstracting from money and formulating monetary policy as a nominal interest rate (Taylor) rule. Woodford (2003), while providing a thorough analysis of many aspects of the New-Keynesian framework, discusses the role of capital only briefly. Galí and Gertler (2007) lay out the New-Keynesian model with capital, but do not discuss the transmission mechanism, focusing instead on the role of expectations and the frictionless equilibrium in the conduct of monetary policy.
} 
The purpose of this article, therefore, is to carefully lay out the internal mechanism of the New-Keynesian model, with a particular focus on the role of capital - the key ingredient in the transition from the basic framework to the medium-scale DSGE models. The presence of capital - an endogenous state variable - introduces internal dynamics into the model by allowing households, in the aggregate, to smooth out the effects of fluctuations in output, and thus income, on consumption. We explain the effect of capital on the internal mechanism of the New-Keynesian model in a step-by-step fashion, starting with the basic framework. We argue that the extended model better reveals the underlying transmission mechanism of monetary policy in New-Keynesian models and that the lessons learned in the model with capital apply also to the basic framework.

The motivation behind the development of New-Keynesian models was the desire to introduce the traditional Keynesian real interest rate channel of monetary policy transmission, used in practical monetary policy debates, into a modern dynamic general equilibrium environment. Indeed, the real effects of monetary policy in New-Keynesian models are often explained as operating through this mechanism (e.g., Ireland, 2015). Standard textbook interpretations also invoke the real rate channel (e.g. Galí, 2015, Chapter 1). According to the real rate channel, the central bank - controlling the short-term nominal interest rate - has leverage over the ex-ante real interest rate because nominal prices are sticky. An increase in the nominal rate, for example, leads to an increase in the real rate, which in turn reduces consumption and investment by households and firms, and thus aggregate demand and output. This puts pressure on firms to gradually adjust prices to a lower level (Bernanke and Gertler, 1995; Mishkin, 1996, provide a detailed discussion of the real rate channel). Unexpected monetary policy tightening transmitting through this channel should thus, in equilibrium, deliver declines in output and inflation accompanied by an increase in the nominal and ex-ante real interest rates. $^{2}$

\footnotetext{
${ }^{2}$ The emphasis of the theoretical literature on the real rate channel is partly motivated by a large empirical literature documenting that, broadly speaking, in response to a positive innovation in a short-term nominal interest rate: (i) the nominal interest rate increases, (ii) output declines, and (iii) inflation (persistently) declines, but less than output. The ex-ante real interest rate increases as a result of (i) and (iii). These empirical properties are based on impulse-responses from structural VARs (see, e.g., Walsh, 2010, Chapter
} 
We demonstrate the following properties of the New-Keynesian model: (i) even in the basic three-equation version, generating all of the above responses to a monetary policy shock depends on parameterization, (ii) consumption smoothing works against the desirable responses, and (iii) the presence of capital reveals that, in general, the real effects of monetary policy in the New-Keynesian model have little to do with the real rate channel; in fact, declines in output and inflation in response to a positive monetary policy shock are consistent with a fall, increase, or no change in the ex-ante real interest rate.

The effect of capital on the equilibrium of the New-Keynesian model has a flavor of findings in the asset pricing literature. Jermann (1998) and Tallarini (2000), for instance, show that desirable asset pricing properties established in economies without capital are much harder to obtain in models that allow capital accumulation. Similarly here, the desirable responses to a monetary policy shock that can be established in a New-Keynesian model without capital are much harder to get in a version with capital. Like in the asset pricing literature, sufficiently high capital adjustment costs need to be introduced to reverse this result (infinite adjustment costs replicate the equilibrium of the model without capital). However, while capital adjustment costs make the model consistent with the real rate channel, the consistency is in general only observational. ${ }^{3}$

If not through the real rate channel, how does then monetary policy transmit into output and inflation in the New-Keynesian model? We argue that, as a first pass, one can think of the transmission mechanism as follows. The Euler equation for bonds (the Fisher equation) together with the Taylor rule pin down inflation almost in the same way as in a flexible price model-inflation, first and foremost, depends on current and expected future shocks to the Taylor rule. Given the path of the inflation rate, the New-Keynesian Phillips curve then determines output. The real rate largely only reflects the desire and ability of households to smooth consumption in response to changes in income (output). In the model without

1, for an overview). Over time, the literature has achieved great success in matching the size and timing of these responses by extending the basic model in several dimensions (Christiano et al., 2005).

${ }^{3}$ Previously, Cochrane (2011) critiqued the common arguments used in the literature to select a unique inflation process in New-Keynesian models for assuming the presence of the real rate channel. 
capital, consumption smoothing in the aggregate is not possible. In order for this to occur in equilibrium, the real interest rate has to adjust; it has to increase when output drops to prevent borrowing. The equilibrium outcome of the model without capital thus makes it appear as if monetary policy affected output and inflation through the real rate channel. This intuition proves wrong once capital is introduced.

Not to duplicate well-know derivations from first principles, the starting point of our analysis is the set of conditions characterizing the general equilibrium. The description of the mechanism then builds on the linearized versions of these conditions. We express the endogenous variables as linear functions of state variables and obtain analytical solutions for these functions using the method of undetermined coefficients. The analytical solutions are then relied on as much as possible to describe the workings of the model. When insight from the analytical solutions is limited, numerical analysis is used to explore how the equilibrium functions depend on parameter values. ${ }^{4}$

We do not discuss optimal policy as this is well covered by existing texts. For this reason we are not concerned with the concepts of an output gap and the natural real interest rate. The policy implication of our analysis is that (i) either monetary policy in actual economies does transmit through the real interest rate channel, but then the New-Keynesian model is not suitable for its analysis or (ii) the New-Keynesian model is a useful description of actual economies, but then policy makers relying on this framework need to rethink the way monetary policy transmits into inflation and real activity.

The paper is divided into two main sections. Section 2 deals with the basic model without capital. Section 3 demonstrates how the key properties of the model change once capital is introduced. Section 4 concludes. Secondary material is contained in an Appendix.

\footnotetext{
${ }^{4}$ The New-Keynesian model is usually studied under the assumption that the nominal interest rate can increase or decrease without any constraint. Our analysis is carried out in this tradition. A few recent studies focus on the model's behavior at the zero lower bound. Cochrane (2016), for instance, shows that at the zero lower bound an interest rate peg is stable and inflation is first and foremost determined by the Fisher effect. Bullard (2015) uses this analysis in his discussion of the recent nominal environment in G7 countries. Kocharlakota (2016) takes a different view, arguing that at the zero lower bound, monetary policy can have large real effects even when the Phillips curve is only slightly less than vertical.
} 


\section{The basic model without capital}

The basic model serves the purpose of deriving results that are used as a basis for our discussion of the role of capital. To set notation, the exposition is based on a standard per-period utility function

$$
u=\log c-\frac{l^{1+\eta}}{1+\eta}, \quad \eta \geq 0,
$$

and an intermediate goods aggregator

$$
y=\left[\int y(j)^{\varepsilon} d j\right]^{\frac{1}{\varepsilon}}, \quad \varepsilon \in(0,1),
$$

of the typical intermediate-final producer setup of the model. The starting point of our analysis is the system of equations describing the general equilibrium, with the New-Keynesian Phillips curve (NKPC) already in its linearized form, around the zero steady-state inflation rate, the usual approximation point in the literature. ${ }^{5}$ The derivation of this system from first principles can be found, for instance, in Walsh (2010) and Galí (2015). In the spirit of Woodford (2003) and much of the literature that followed, the economy is cashless and monetary policy is formulated as a Taylor-type rule. The general equilibrium is characterized by

$$
\begin{gathered}
\frac{w_{t}}{c_{t}}=l_{t}^{\eta}, \\
\frac{1}{c_{t}}=\beta E_{t}\left(\frac{1}{c_{t+1}} \frac{1+i_{t}}{1+\pi_{t+1}}\right), \\
y_{t}=l_{t}, \\
\chi_{t}=w_{t}, \\
\pi_{t}=-\frac{1}{\phi(\varepsilon-1)}\left(\chi_{t}-\chi\right)+\beta E_{t} \pi_{t+1},
\end{gathered}
$$

\footnotetext{
${ }^{5}$ Most of the literature works with approximation around zero inflation steady state as this yields a simplelooking NKPC allowing a straightforward interpretation. Through out the paper, we therefore proceed in this tradition. Nevertheless, all the results presented in this paper were cross-checked against results obtained for a nonzero inflation steady-state approximation, using Rotemberg price setting, without detecting any significant differences.
} 


$$
\begin{gathered}
i_{t}=i+\nu \pi_{t}+\xi_{t}, \\
y_{t}=c_{t} .
\end{gathered}
$$

Here, $c_{t}$ is consumption, $w_{t}$ is a real wage rate, $l_{t}$ is labor, $i_{t}$ is a one-period nominal interest rate, $\pi_{t}$ is the inflation rate between periods $t-1$ and $t, y_{t}$ is output, $\chi_{t}$ is the marginal cost, and $\xi_{t}$ is a standard mean-zero monetary policy shock. Equation (1) is the consumer's first-order condition for labor, equation (2) is the Euler equation for a one-period nominal bond, which is in zero net supply, equation (3) is a production function, equation (4) gives the marginal cost, equation (5) is the NKPC (for the Rotemberg, 1982, quadratic price adjustment cost specification), equation (6) is the Taylor rule, and equation (7) is the goods market clearing condition. In the NKPC, $\phi \geq 0$ is the Rotemberg cost parameter. Further, $\beta \in(0,1)$ is a discount factor and $\nu>1$ is the weight on inflation in the Taylor rule. Variables without a time subscript denote steady-state values (the steady-state value of the inflation rate is equal to zero).

For the points made in this paper, the exposition is cleaner when the weight on output in the Taylor rule is set equal to zero, as implicitly assumed in equation (6). The main text also deals only with a Taylor rule that responds to current inflation. The appendix derives results for forward- and backward-looking Taylor rules and shows that those alternative specifications do not change the main points made here.

The linearized NKPC is derived for the Rotemberg specification. It is, however, wellknown that the same form is obtained also for the Calvo (1983) specification. ${ }^{6}$ Namely, under Calvo specification,

$$
\pi_{t}=\frac{(1-\theta)(1-\theta \beta)}{\theta}\left(\chi_{t}-\chi\right)+\beta E_{t} \pi_{t+1}
$$

\footnotetext{
${ }^{6}$ The Calvo specification leads to an aggregation bias that shows up as total factor productivity in the production function (3). This bias, however, disappears once the model is linearized around the zero inflation steady state. The Rotemberg specification, on the other hand, leads to a resource loss that shows up in the goods market clearing condition (7). Again, it disappears in a linearized version of the model. For these reasons, the above general equilibrium system abstracts from these two details.
} 
where $\theta \in[0,1]$ is the fraction of producers not adjusting prices in a given period. The mapping between Rotemberg and Calvo NKPC is thus

$$
\frac{(1-\theta)(1-\theta \beta)}{\theta}=-\frac{1}{\phi(\varepsilon-1)}>0 .
$$

The endogenous variables in the system (1)-(7) are $c_{t}, w_{t}, l_{t}, i_{t}, \pi_{t}, y_{t}$, and $\chi_{t}$. The exogenous variable is the monetary policy shock $\xi_{t}$. In the model without capital, the shock is the only state variable. In a linear solution, the dynamics of the endogenous variables are thus fully governed by the exogenous process for the shock; the model parameters affect only the sign and size of the responses of the endogenous variables to the shock. ${ }^{7}$

Eliminating equations (1), (3), (4), and (7) by substitutions for $c_{t}, l_{t}, w_{t}$, and $\chi_{t}$, the system can be reduced to a three-equation system, which when log-linearized around a steady state (with $y=1$ ) becomes

$$
\begin{gathered}
-\widehat{y}_{t}=-E_{t} \widehat{y}_{t+1}+\widehat{i}_{t}-E_{t} \pi_{t+1}, \\
\pi_{t}=\Omega \widehat{y}_{t}+\beta E_{t} \pi_{t+1}, \\
\widehat{i}_{t}=\nu \pi_{t}+\xi_{t} .
\end{gathered}
$$

Here, $\widehat{i}_{t} \equiv i_{t}-i$ and $\widehat{y}_{t} \equiv\left(y_{t}-y\right) / y$. Further, $\Omega \equiv-(1+\eta) /[\phi(\varepsilon-1)]=(1+\eta)(1-\theta)(1-$ $\theta \beta) / \theta>0$, depending on whether Rotemberg or Calvo NKPC is used. The ex-ante real interest rate is defined as $\widehat{R}_{t} \equiv \widehat{i}_{t}-E_{t} \pi_{t+1}$, which from equation (9) implies $\widehat{R}_{t}=E_{t} \widehat{y}_{t+1}-\widehat{y}_{t}$. The system (9)-(11) is the usual three-equation representation of the basic New-Keynesian model.

\footnotetext{
${ }^{7}$ As we are not concerned with optimal policy, we do not proceed to further normalize the variables as deviations from flexible-price levels. To study the model dynamics in response to a monetary policy shock, it is sufficient to work with the deviations from steady state, as the nominal shock does not affect the flexible-price levels.
} 


\subsection{Equilibrium output and inflation}

It is convenient to reduce the above system further by substituting out $i_{t}$ from equation (11) to get two equations in two endogenous variables, $\pi_{t}$ and $y_{t}$,

$$
\begin{gathered}
-\widehat{y}_{t}=-E_{t} \widehat{y}_{t+1}+\nu \pi_{t}+\xi_{t}-E_{t} \pi_{t+1} \\
\pi_{t}=\Omega \widehat{y}_{t}+\beta E_{t} \pi_{t+1} .
\end{gathered}
$$

The system (12)-(13) can be solved by, for instance, the method of undetermined coefficients. Assume that the equilibrium decision rule and pricing function are linear functions of the state variable

$$
\widehat{y}_{t}=a \xi_{t} \quad \text { and } \quad \pi_{t}=b \xi_{t}
$$

where $a$ and $b$ are unknown. The guesses are linear, rather than affine, functions of the state as the variables are expressed as deviations from steady state, and thus are equal to zero when $\xi_{t}=0$. Suppose that the monetary policy shock follows a stationary AR(1) process

$$
\xi_{t+1}=\rho \xi_{t}+\epsilon_{t+1}, \quad \rho \in[0,1)
$$

where $\epsilon_{t+1}$ is an innovation. Substituting the guesses into the system (12)-(13), evaluating the expectations using the $\mathrm{AR}(1)$ process, and aligning terms gives unique equilibrium coefficients

$$
\begin{gathered}
a=-\frac{1-\beta \rho}{(1-\rho)(1-\beta \rho)+\Omega(\nu-\rho)}<0, \\
b=-\frac{1}{(1-\rho) \frac{1-\beta \rho}{\Omega}+(\nu-\rho)}<0 .
\end{gathered}
$$

\subsubsection{Flexible prices}

It is illustrative to consider two extreme cases of price stickiness. First, suppose that prices are fully flexible $(\theta \rightarrow 0$ or $\phi \rightarrow 0 \Rightarrow \Omega \rightarrow \infty)$. One reason for considering this case is that 
the solution for inflation under this assumption approximates the solution for inflation under sticky prices once capital is introduced into the model. In the present model, under flexible prices,

$$
a \rightarrow 0 \quad \text { and } \quad b \rightarrow-\frac{1}{\nu-\rho}<0
$$

Output in this case is unaffected by the monetary policy shock. The coefficient $b$ is greater in absolute value the more persistent is the shock. The equilibrium coefficient $b$ under flexible prices can be alternatively obtained by solving forward equation (12), with $\widehat{y}_{t}=0$, and excluding explosive paths for inflation (the 'bubble term')

$$
\pi_{t}=-\frac{1}{\nu} \sum_{j=0}^{\infty}\left(\frac{1}{\nu}\right)^{j} E_{t} \xi_{t+j}=-\frac{1}{\nu-\rho} \xi_{t} .
$$

This equation makes it clear that inflation is determined only by the expected path of the monetary policy shock, with the real rate playing no role in its determination. We refer to this as a 'Fisherian principle'.

Why is the response of inflation to a positive monetary policy shock negative under flexible prices? To answer this question, it is helpful to rewrite the monetary policy rule (6) as

$$
i_{t}=\left(i+\zeta_{t}\right)+\nu\left(\pi_{t}-\zeta_{t}\right)
$$

where the new shock $\zeta_{t}$ is related to the original shock as $\zeta_{t} \equiv-(\nu-1)^{-1} \xi_{t}$. The shock $\zeta_{t}$ thus inherits the persistence of the original shock but the two shocks are negatively related. When the policy rule is rewritten as equation (17), the shock $\zeta_{t}$ has an interpretation as an inflation target shock (e.g., Smets and Wouters, 2003; Ireland, 2007). This reformulation makes it easier to see why, when $\xi_{t}$ increases (the inflation target declines), the inflation rate declines. 


\subsubsection{Fixed prices}

Second, suppose that prices are completely fixed $(\theta \rightarrow 1$ or $\phi \rightarrow \infty \Rightarrow \Omega \rightarrow 0)$. This case is useful as it shows why the New-Keynesian model can be perceived as working through the real rate channel. When prices are completely fixed

$$
a \rightarrow-\frac{1}{1-\rho}<0 \quad \text { and } \quad b \rightarrow 0
$$

Now, inflation is unaffected by monetary policy and the response of output is greater (in absolute value) the more persistent is the monetary policy shock. Observe that when prices are completely fixed, output is fully determined by the Euler equation (9) and the monetary policy rule (11), both of which have $\pi_{t}=0 \forall t$ (on the production side, as $\Omega \rightarrow 0$, producers become increasingly sensitive to any given change in inflation and in the limit find any output level optimal; see the NKPC). Combining equations (9) and (11) yields

$$
E_{t} \widehat{y}_{t+1}-\widehat{y}_{t}=\xi_{t}
$$

where the monetary policy shock translates one-for-one to the ex-ante real interest rate, $\xi_{t}=\widehat{i}_{t}=\widehat{R}_{t}$. Monetary policy thus operates through the real rate channel and is completely in control of output.

Why is the response of output to a positive $\xi_{t}$ shock negative? According to equation (18), output is expected to grow as long as $\xi_{t}$ is positive (the ex-ante real interest rate is above steady state). Because the model is stationary $-\xi_{t}$ is governed by a stationary $\operatorname{AR}(1)$ process - the only way output can grow is if it falls, on the impact of the shock, below its steady state level. 


\subsubsection{Back to the general case}

In general, the combination of the Euler equation (9) and the Taylor rule (11) yields

$$
\pi_{t}=-\frac{1}{\nu} \sum_{j=0}^{\infty}\left(\frac{1}{\nu}\right)^{j} E_{t} \xi_{t+j}+\frac{1}{\nu} \sum_{j=0}^{\infty}\left(\frac{1}{\nu}\right)^{j} E_{t} \widehat{R}_{t+j}
$$

where $\widehat{R}_{t+j}=E_{t+j} \widehat{y}_{t+1+j}-\widehat{y}_{t+j}$. Under flexible prices, only the first infinite sum determines inflation, as in equation (16). Under fixed prices, the two infinite sums exactly cancel each other out. Except for this case, however, the first infinite sum dominates and the response of inflation to a positive monetary policy shock is negative, as reflected by the equilibrium coefficient $b<0$, given by (15). Observe that whenever the real rate increases, it mitigates the negative effect of the positive monetary policy shock on inflation.

The reduced form parameter $\Omega$ in equations (14) and (15) works like a weight shifting the equilibrium coefficients between the fully flexible and completely fixed price solutions. The quantitative effects of price stickiness on the equilibrium coefficients are explored in the upper-left panel of Figure 1, which plots $a$ and $b$ against the structural parameter $\theta$ (the other parameters are $\beta=0.99, \eta=1, \nu=1.5$, and $\rho=0.5$; all fairly standard values in the literature). Observe that, as noted above, the equilibrium responses of output and inflation are always negative and varying $\theta$ moves the equilibrium coefficients between the two extreme cases of price stickiness. The typical estimates of $\theta$ in the literature are between 0.5 and 0.9 for a quarterly model, depending on the time period and country. ${ }^{8}$

The lower-left panel of Figure 1 demonstrates the effect of $\rho$ (for $\theta=0.7$, a mid-point in the range of typical values, implying average price stickiness of 3.3 quarters). Notice that as $\rho \rightarrow 1$, the equilibrium coefficients converge, approximately, to the flexible-price solution (the convergence can be arbitrarily close the closer is $\beta$ to one). This is because, in the NKPC, output depends (approximately, for $\beta$ close to one) on the expected change in the inflation

\footnotetext{
${ }^{8}$ The advantage of using the Calvo specification of the NKPC for numerical examples is that the literature contains a rich set of estimates of $\theta$. Further, $\theta$ can be directly translated into the number of periods prices are on average fixed, as $(1-\theta)^{-1}$.
} 
rate. Thus, the more persistent is inflation, the smaller is its period-on-period change and thus the smaller is its effect on output.

\subsection{Equilibrium nominal and real rates}

The equilibrium functions for the nominal and ex-ante real interest rates can be derived, respectively, as

$$
\widehat{i}_{t}=\nu \pi_{t}+\xi_{t}=(1+\nu b) \xi_{t}
$$

and

$$
\widehat{R}_{t} \equiv \widehat{i}_{t}-E_{t} \pi_{t+1}=(1+\nu b-\rho b) \xi_{t},
$$

where $b<0$ is given by (15). The equilibrium nominal interest rate consists of two terms: a direct effect of the shock in the Taylor rule and an indirect effect due to the response of monetary policy to the equilibrium inflation rate. While the first effect is positive, the second effect is negative and its absolute value, as noted in the previous subsection, increases with the persistence of the shock. The sign of the effect of the monetary policy shock on the equilibrium nominal interest rate thus depends on the persistence of the shock.

The equilibrium ex-ante real interest rate depends on three effects. In addition to the above two effects, it also directly depends on expected inflation, captured by the term $-\rho b$. Like the direct effect of the shock, the expected inflation effect is positive, as $b<0$. Substituting in for $b$ and rearranging terms gives

$$
\widehat{R}_{t}=\left(1-\frac{1}{1+\frac{1-\rho}{\nu-\rho} \frac{1-\beta \rho}{\Omega}}\right) \xi_{t}
$$

where the expression in the brackets is positive, as the term in the denominator is greater than one. The two positive effects thus always dominate the negative effect. ${ }^{9}$

\footnotetext{
${ }^{9}$ Alternatively, one can see that the ex-ante real interest rate always responds positively to the $\xi_{t}$ shock by recalling that output always declines on impact of the shock ( $a$ is always negative) and converges back to its steady state from that point on (i.e., it is growing). This can only happen, according to the Euler equation, if the deviation from steady state of the ex-ante real interest rate is positive.
} 
The right-hand side panels of Figure 1 show the effects of $\theta$ and $\rho$ on the equilibrium nominal and ex-ante real interest rates. As expected, the equilibrium coefficient of the real rate is always positive. Notice, however, that for a significant part of the parameter space $(\theta<0.5$ or $\rho>0.7)$, the equilibrium coefficient of the nominal rate is negative - the indirect effect of the shock, working through the response of monetary policy to the decline of inflation, dominates the direct effect.

To sum up, for most of the parameter space the responses of the basic model are in line with the real rate channel: in response to a monetary policy shock, output and inflation decline while the nominal and ex-ante real interest rates increase. For $\theta<0.5$ or $\rho>0.7$, however, declines of output and inflation are accompanied by an increase in the real rate, but a decline in the nominal rate. While such parameterization may not be empirically interesting, it nevertheless sends a warning signal that the usual interpretation of the monetary transmission mechanism in the New-Keynesian model may be at odds with the inner workings of the model. Furthermore, equation (19) makes it clear that the reason why inflation declines in response to the positive monetary policy shock is the first (Fisherian) term in the equation, not the increase in the real rate (the second term), as suggested by the real rate channel. The increase in the real rate, in fact, works against the decline in inflation.

\section{The model with capital}

When capital is introduced into the model, the general equilibrium becomes characterized by the following system

$$
\begin{gathered}
\frac{w_{t}}{c_{t}}=l_{t}^{\eta}, \\
\frac{1}{c_{t}}=\beta E_{t}\left[\frac{1}{c_{t+1}}\left(\frac{1+i_{t}}{1+\pi_{t+1}}\right)\right], \\
\frac{1}{c_{t}}=\beta E_{t}\left[\frac{1}{c_{t+1}}\left(1+r_{t+1}-\delta\right)\right], \\
y_{t}=k_{t}^{\alpha} l_{t}^{1-\alpha},
\end{gathered}
$$




$$
\begin{gathered}
\frac{w_{t}}{r_{t}}=\frac{1-\alpha}{\alpha}\left(\frac{k_{t}}{l_{t}}\right), \\
\chi_{t}=\left(\frac{r_{t}}{\alpha}\right)^{\alpha}\left(\frac{w_{t}}{1-\alpha}\right)^{1-\alpha}, \\
\pi_{t}=\Psi \widehat{\chi}_{t}+\beta E_{t} \pi_{t+1}, \\
i_{t}=i+\nu \pi_{t}+\xi_{t}, \\
y_{t}=c_{t}+k_{t+1}-(1-\delta) k_{t} .
\end{gathered}
$$

Here, $k_{t}$ is capital, $r_{t}$ is the capital rental rate, and $\delta \in(0,1)$ is a depreciation rate; investment can be defined residually as $x_{t} \equiv k_{t+1}-(1-\delta) k_{t}$. Further, $\widehat{\chi}_{t} \equiv\left(\chi_{t}-\chi\right) / \chi$ and $\Psi \equiv$ $-\chi /[\phi(\varepsilon-1)]=[(1-\theta)(1-\theta \beta) / \theta] \Theta>0$, where $\Theta \equiv \frac{1-\alpha}{1-\alpha+\alpha /(1-\varepsilon)}$, is a new elasticity of inflation to the marginal cost, expressed for the Rotemberg and Calvo specifications, respectively. The endogenous variables are $c_{t}, w_{t}, l_{t}, i_{t}, \pi_{t}, y_{t}, \chi_{t}, r_{t}, k_{t}$; the exogenous variables are $\xi_{t}$ and $k_{0} \cdot{ }^{10}$

Notice that (21), (22), and (28) are the same as before. Further, (24), (26), and (27) are the same as before for $\alpha=0$. The truly new equations are equations (23) and (25), which add the two new endogenous variables, $k_{t}$ and $r_{t}$. Equation (23) is the Euler equation for capital and equation (25) is a condition for the optimal mix of capital and labor in production; it equates the marginal rate of technological substitution with the relative factor prices (a first-order condition of a cost minimization problem of each firm $j$ ).

This model contains the key element of a prototypical real business cycle (RBC) model: capital accumulation as a means for the economy as a whole to smooth out consumption in the presence of fluctuations in income (output). In fact, under flexible prices, the model collapses into a RBC model with two additions, the Euler equation for bonds and the Taylor rule. To see this, note that under flexible prices, $\Psi \rightarrow \infty$. The NKPC (27) then implies $\widehat{\chi}_{t}=$ 0, or $\chi_{t}=\chi$. If, in addition, $\varepsilon=1$ (perfect competition), $\chi=1$; see Galí (2015), Chapter

\footnotetext{
${ }^{10} \mathrm{As}$ in the baseline model, for the reasons discussed earlier, the exposition abstracts from the aggregation bias in the case of Calvo pricing and the resource loss in the case of Rotemberg pricing.
} 
3. This is a standard profit maximization condition under perfect competition, stating that the marginal cost is equal to the good's relative price, which is equal to one, as all goods are perfect substitutes. When this condition is used in equation (26), and the resulting equation is combined with the cost minimization condition (25), we get the standard RBC conditions equalizing marginal products to factor prices: $r_{t}=\alpha k_{t}^{\alpha-1} l_{t}^{1-\alpha}$ and $w_{t}=(1-\alpha) k_{t}^{\alpha} l_{t}^{-\alpha}$. Under flexible prices, these two conditions replace equations (25) and (26) in the above system. Notice that the system becomes recursive (a classical dichotomy): equations (21), (23), (24), (29), and the above two marginal product conditions - the standard RBC system - determine $c_{t}, w_{t}, l_{t}, y_{t}, r_{t}$, and $k_{t}$, given $k_{0}$, independently of $\xi_{t}$ (in addition, $\chi_{t}=1$ from the NKPC). Equations (22) and (28) then pin down $i_{t}$ and $\pi_{t}$. The $\operatorname{NKPC}(27)$, with $\Psi<\infty$, is what breaks the classical dichotomy.

\subsection{The log-linear system}

In what follows it is convenient to substitute in for $r_{t}$ in the expression for the marginal cost (26) from the cost minimization condition (25). The marginal cost then becomes

$$
\chi_{t}=\frac{w_{t}}{1-\alpha}\left(\frac{y_{t}}{k_{t}}\right)^{\frac{\alpha}{1-\alpha}} .
$$

Observe that for $\alpha=0$ this expression becomes the same as in the model without capital. Further, substitute in for $l_{t}$ in the first-order condition for labor (21) from the production function (24). This gives the first-order condition for labor as

$$
\frac{w_{t}}{c_{t}}=\left(\frac{y_{t}}{k_{t}^{\alpha}}\right)^{\frac{\eta}{1-\alpha}} .
$$

Again, for $\alpha=0$, this condition is the same as in the model without capital.

With the above two substitutions, we can log-linearize the general equilibrium system to get

$$
-\widehat{c}_{t}+\widehat{w}_{t}=\frac{\eta}{1-\alpha} \widehat{y}_{t}-\frac{\alpha \eta}{1-\alpha} \widehat{k}_{t}
$$




$$
\begin{gathered}
-\widehat{c}_{t}=-E_{t} \widehat{c}_{t+1}+\widehat{i}_{t}-E_{t} \pi_{t+1}, \\
-\widehat{c}_{t}=-E_{t} \widehat{c}_{t+1}+E_{t} \widehat{r}_{t+1}, \\
\widehat{l}_{t}=\frac{1}{1-\alpha} \widehat{y}_{t}-\frac{\alpha}{1-\alpha} \widehat{k}_{t}, \\
\widehat{r}_{t}=r\left(\widehat{l}_{t}-\widehat{k}_{t}+\widehat{w}_{t}\right), \\
\widehat{\chi}_{t}=\widehat{w}_{t}+\frac{\alpha}{1-\alpha} \widehat{y}_{t}-\frac{\alpha}{1-\alpha} \widehat{k}_{t}, \\
\pi_{t}=\Psi \widehat{\chi}_{t}+\beta E_{t} \pi_{t+1}, \\
\widehat{i}_{t}=\nu \pi_{t}+\xi_{t}, \\
\widehat{y}_{t}=\frac{c}{y} \widehat{c}_{t}+\frac{k}{y} \widehat{k}_{t+1}-(1-\delta) \frac{k}{y} \widehat{k}_{t} .
\end{gathered}
$$

Here, variables without time subscripts are steady-state values, interest rates are expressed as percentage point deviations from steady state, $\widehat{r}_{t} \equiv r_{t}-r, \widehat{i}_{t} \equiv i_{t}-i$, and all other variables are expressed as percentage deviations from steady state, e.g., $\widehat{c}_{t} \equiv\left(c_{t}-c\right) / c$. Eliminating $\widehat{r}_{t}, \widehat{\chi}_{t}, \widehat{w}_{t}, \widehat{i}_{t}$, and $\widehat{l}_{t}$ we get a final system of four equilibrium first-order difference equations in four endogenous variables $\widehat{c}_{t}, \widehat{y}_{t}, \widehat{k}_{t}$, and $\widehat{\pi}_{t}$

$$
\begin{gathered}
-\widehat{c}_{t}=-E_{t} \widehat{c}_{t+1}+\nu \pi_{t}-E_{t} \pi_{t+1}+\xi_{t}, \\
-\widehat{c}_{t}=-E_{t} \widehat{c}_{t+1}+r E_{t}\left(\widehat{c}_{t+1}+\frac{1+\eta}{1-\alpha} \widehat{y}_{t+1}-\frac{1+\alpha \eta}{1-\alpha} \widehat{k}_{t+1}\right), \\
\pi_{t}=\Psi\left[\frac{\eta+\alpha}{1-\alpha} \widehat{y}_{t}-\frac{\alpha(1+\eta)}{1-\alpha} \widehat{k}_{t}+\widehat{c}_{t}\right]+\beta E_{t} \pi_{t+1}, \\
\widehat{y}_{t}=\frac{c}{y} \widehat{c}_{t}+\frac{k}{y} \widehat{k}_{t+1}-(1-\delta) \frac{k}{y} \widehat{k}_{t} .
\end{gathered}
$$

Here, (30) is the same as in the model without capital, (33) is the same as in the model without capital for $k=0$, and (32) is the same as in the model without capital for $\widehat{k}_{t}=0$ and $\alpha=0$. Equation (31) is new and capital accumulation disrupts the close connection 
between consumption and output in the basic model, as here investment implies $\widehat{c}_{t} \neq \widehat{y}_{t}$.

Observe that when prices are fully flexible $(\Psi \rightarrow \infty)$, the NKPC (32) implies that, given a steady-state initial condition $\left(\widehat{k}_{t}=0\right), \widehat{c}_{t}=\widehat{y}_{t}=0$. Equation (33) then implies $\widehat{k}_{t+1}=0$. Monetary policy is neutral and inflation is determined from equation (30) in exactly the same way as under flexible prices. The addition of capital thus does not change consumption or inflation responses to the monetary policy shock when prices are fully flexible.

Consider now the other extreme, when prices are completely fixed $(\Psi \rightarrow 0)$. Now, like in the model without capital, the NKPC (32) implies that inflation is equal to zero. Further, equation (30) determines consumption as a function of the monetary policy shock in the same way as in the model without capital and a positive monetary policy shock reduces consumption. The presence of capital thus has no effect on equilibrium inflation and consumption when prices are completely fixed. The interesting case is the one in-between the two extremes, to which we turn next.

\subsection{The real effects of monetary policy shocks - a first look}

According to the common interpretation of the monetary transmission mechanism in the New-Keynesian model as a real rate channel, a positive shock to the Taylor rule increases the nominal interest rate. Because prices are sticky, the ex-ante real interest rate also increases, which suppresses aggregate demand, as consumers postpone consumption and producers cut down on investment. As producers find it costly to adjust prices in face of a decline in demand, they cut production and aggregate output falls. While this interpretation may be observationally equivalent to the mechanism in the basic model - in which a decline in output is always accompanied by an increase in the ex-ante real rate, though not necessarily the nominal rate - it is hard to justify in the model with capital. Here we take a first look at this issue and revisit it in the sections that follow.

For the purpose of the exposition, it is helpful to assume that the steady-state capital rental rate $r$ is small enough to be approximated by zero (under standard parameterizations, 
it is around 0.03 , given by $1 / \beta-1+\delta$ ). Under this assumption, equation (31) implies $\widehat{c}_{t}=E_{t} \widehat{c}_{t+1}$; that is, the presence of capital allows perfect consumption smoothing across time. Further, as the model is stationary (see below), it then has to be the case that $\widehat{c}_{t}=E_{t} \widehat{c}_{t+1}=0$. Otherwise, under $\widehat{c}_{t}=E_{t} \widehat{c}_{t+1}$, a given shock would lead to a permanent shift of consumption away from the steady state, which violates stationarity. With consumption thus determined, equation (30) then determines the equilibrium inflation rate, which depends only on the monetary policy shock. The solution for the inflation rate is therefore the same as in the model without capital under flexible prices, $\pi_{t}=-[1 /(\nu-\rho)] \xi_{t}$. The inflation rate falls on the impact of the shock and converges back to zero from below. Along this path, $\pi_{t}-E_{t} \pi_{t+1}$ is negative. Thus, for $\beta$ close to one, equation (32) implies that on the impact of the shock output has to decline. This is because $\widehat{c}_{t}=0$ for the above reasons and $\widehat{k}_{t}=0$, as in the impact period the existing capital stock is in steady state. From equation $(33), \widehat{k}_{t+1}$ then has to decline; i.e., the decline in output is fully absorbed by a decline in investment. As will be demonstrated below, in the actual solution, the decline in next period's capital stock leads to a decline in next period's consumption, relative to today's, and thus to a decline in the ex-ante real interest rate.

To sum up, equilibrium inflation in the model with capital is approximately determined by the Fisherian principle (current and expected future monetary policy shocks), while equilibrium output is determined by the Keynesian principle (the New-Keynesian Phillips curve). The real rate only reflects the effects of consumption smoothing. While this description provides a simplifying account of the model's dynamics, the sections below show that it provides a useful way to think about the real effects of monetary policy in the New-Keynesian model. 


\subsection{Equilibrium functions and impulse-responses}

The model can be again solved by the method of undetermined coefficients. There are two state variables, $k_{t}$ and $\xi_{t}$. The general solution thus has the form:

$$
\widehat{c}_{t}=a_{0} \widehat{k}_{t}+a_{1} \xi_{t}, \quad \pi_{t}=b_{0} \widehat{k}_{t}+b_{1} \xi_{t}, \quad \widehat{y}_{t}=d_{0} \widehat{k}_{t}+d_{1} \xi_{t}, \quad \text { and } \quad \widehat{k}_{t+1}=f_{0} \widehat{k}_{t}+f_{1} \xi_{t} .
$$

Substituting these functions into equations (30)-(33), evaluating expectations and collecting terms, yields a system of eight equations in eight unknowns, the coefficients of the equilibrium functions. The resulting system is provided in the Appendix. It is recursive, whereby $a_{0}$, $b_{0}, d_{0}$, and $f_{0}$ can be solved for independently of $a_{1}, b_{1}, d_{1}$, and $f_{1}$. The persistence of the shock, $\rho$, thus has no effect on the equilibrium coefficients loading onto $\widehat{k}_{t}$. In other words, the internal dynamics of the model are unaffected by the dynamics of the shock. The equilibrium coefficients loading onto $\widehat{k}_{t}$, however, affect $a_{1}, b_{1}, d_{1}$, and $f_{1}$ and thus the responses of the endogenous variables to the monetary policy shock. In other words, the presence of capital affects the responses of the endogenous variables to the shock.

From here, we proceed numerically, using the following parameter values: $\beta=0.99$, $\eta=1, \theta=0.7, \nu=1.5$ (same as before) and $\delta=0.025, \alpha=0.3$, and $\varepsilon=0.83$ (fairly standard values). The persistence parameter of the monetary policy shock is again treated as a free parameter. We consider five values, $\rho \in\{0,0.1,0.5,0.95,0.995\}$.

Figures 2-6 display responses to a 1 percentage point increase in $\xi_{t}$ in period $t=1$ for the above five values of $\rho$. Interest rates are reported as percentage point deviations from steady state; all other variables as percentage deviations from steady state. The impulse-response functions reveal our conjecture from the previous subsection that the real effects of monetary policy shocks in the model with capital do not propagate through the real rate channel. In all cases but $\rho=0$, output and inflation fall, in response to the positive monetary policy shock, despite a decline in the ex-ante real interest rate. The nominal interest rate also declines in all but the case of $\rho=0$. 
Experimentation reveals that the nominal rate increases, in response to the shock, only for $\rho \in[0,0.06]$, while both the nominal and real rates increase only for $\rho \in[0,0.04]$; output and inflation, however, fall for all values of $\rho \in[0,1) .{ }^{11}$ This region - in which the model is consistent with the real rate channel - is tiny, compared with the model without capital (refer back to the lower panels of Figure 1).

Regarding consumption and investment, both variables fall, although consumption falls only a little, in line with our discussion in the previous subsection (in the cases of high persistence, consumption increases a little on impact). Further, except the case of $\rho=0$, consumption continues to decline for some time after the shock due to the declining capital stock.

Finally, as $\rho$ gets closer to one, inflation becomes more persistent and the response of output converges to close to monetary policy neutrality, as one would expect from the NKPC, a property in common with the basic model.

\subsection{Consumption smoothing and the real rate}

Why does the model have such a hard time producing an increase in the ex-ante real interest rate in response to the monetary policy shock? We offer explanations from two perspectives, using either the equilibrium inflation or consumption functions. First, as in Section 2, it is helpful to write out the equilibrium function for the real rate as

$$
\begin{aligned}
\widehat{R}_{t} & \equiv \widehat{i}_{t}-E_{t} \pi_{t+1} \\
& =\nu \pi_{t}+\xi_{t}-E_{t} \pi_{t+1} \\
& =\nu\left(b_{0} \widehat{k}_{t}+b_{1} \xi_{t}\right)+\xi_{t}-E_{t}\left(b_{0} \widehat{k}_{t+1}+b_{1} \xi_{t+1}\right)
\end{aligned}
$$

\footnotetext{
${ }^{11}$ In all cases, the real rate increases above its steady-state level several periods after the impact of the shock due to the decline in capital; once the effect of sticky prices (the NKPC) dies off, the dynamics of the real rate become governed by the marginal product of capital, as in a real business cycle model. The decline in capital increases its marginal product.
} 


$$
=b_{0}\left(\nu-f_{0}\right) \widehat{k}_{t}+\left(1+\nu b_{1}-\rho b_{1}-b_{0} f_{1}\right) \xi_{t}
$$

Focus on the immediate response from steady state, thus setting $\widehat{k}_{t}=0$. As an example for the discussion, consider the baseline case of $\rho=0.5$, which yields equilibrium functions $\pi_{t}=-0.057 \widehat{k}_{t}-1.44 \xi_{t}$ and $\widehat{k}_{t+1}=0.936 \widehat{k}_{t}-1.56 \xi_{t}$. For reference, the impulse-responses for this case are in Figure 4.

Observe that the equilibrium coefficient loading onto $\xi_{t}$ in equation (34) consists of four terms. The first three terms, $1+\nu b_{1}-\rho b_{1}$, are the same as in the basic model, even though the value of $b_{1}$ may be different. These are, respectively, the direct effect of the shock on the nominal interest rate, the reaction of monetary policy to the equilibrium response of inflation, and the equilibrium response of expected inflation. In the model without capital, the equilibrium function for inflation (for $\rho=0.5$ ) is $\pi_{t}=-0.35 \xi_{t}$ (see Figure 1), which gave the sum of the three terms being positive (in fact, we proved that the sum of the three terms is always positive in the basic model). Now, however, the coefficient in the equilibrium inflation function loading onto $\xi_{t}$ is equal to -1.44 . This is due to the decline in the real rate, which pushes inflation down above and beyond the effect of the Fisherian principle - refer back to equation (19). As a result, the sum of the three effects is now negative. Furthermore, there is a fourth term in equation $(34),-b_{0} f_{1}$. This term is related to the direct role of capital. Specifically, $f_{1}$ is the equilibrium response of $\widehat{k}_{t+1}$ to $\xi_{t}$ and $b_{0}$ is the equilibrium response of $\pi_{t+1}$ to $\widehat{k}_{t+1}$. The product of $f_{1}$ and $b_{0}$ thus captures the equilibrium response of expected inflation to today's monetary policy shock working through a change in the capital stock. As both $f_{1}$ and $b_{0}$ are negative $\left(f_{1}=-1.56\right.$ and $\left.b_{0}=-0.057\right)$, the product is positive and the capital channel increases inflation expectations, in response to a positive $\xi_{t}$ shock. The capital channel thus further contributes to the decline in the ex-ante real interest rate.

The reason for the negative response of $k_{t+1}$ to the monetary policy shock is consumption smoothing. A decline in output (income) induces consumers to reduce capital to keep consumption as smooth as possible. The reason for the increase in future inflation in response to a decline in future capital stock is the fact that, as explained above, once price stickiness 
dies off, the real rate becomes dominated by the dynamics of the marginal product of capital, which increases as capital stock declines. And a higher real rate contributes positively to inflation - refer again back to equation (19). Future inflation is thus expected to increase with a decline in the capital stock.

The capital accumulation channel plays a negative role even when the first three terms generate a positive response of the ex-ante real rate. For instance, the case of $\rho=0.1$ yields $b_{1}=-0.7$ and thus a positive sum of the first three terms. The fourth term, however, counterweights them and the real rate declines (Figure 3). Out of the five cases considered, only in the case of $\rho=0$ is the sum of the first three terms positive and large enough to dominate the fourth term and thus produce an increase in the real rate (Figure 2).

Second, the effect of consumption smoothing on the response of the ex-ante real rate can also be explained using the equilibrium function for consumption

$$
\widehat{R}_{t}=E_{t} \widehat{c}_{t+1}-\widehat{c}_{t}=a_{0}\left(f_{0}-1\right) \widehat{k}_{t}+\left(\rho a_{1}-a_{1}+a_{0} f_{1}\right) \xi_{t} .
$$

The equilibrium function for consumption is $\widehat{c}_{t}=0.5 \widehat{k}_{t}-0.5 \xi_{t}$. Focus again on the response from steady state $\left(\widehat{k}_{t}=0\right)$. The coefficient loading onto $\xi_{t}$ consists of three terms. The first two terms are the same as in the model without capital, although the value of $a_{1}$ may now be different. The third term is related to the direct role of capital. Here, $f_{1}$ gives again the equilibrium response of $\widehat{k}_{t+1}$ to $\xi_{t}$. Recall that this coefficient is negative, reflecting consumption smoothing in response to a drop in output due to a positive $\xi_{t}$ shock. The coefficient $a_{0}$ gives the equilibrium response of $\widehat{c}_{t+1}$ to $\widehat{k}_{t+1}$. This coefficient is positive, prescribing a lower consumption when capital is lower. The two coefficients together thus prescribe a drop in tomorrow's consumption, relative to consumption today, in response to a positive $\xi_{t}$ shock today. Declining consumption then implies a fall in the ex-ante real rate. The consumer is effectively trading off maintaining relatively high consumption on the impact of the shock (when income declines the most), for a slightly declining consumption path in the immediate future. 


\subsection{Adjustment costs}

Suppose that whenever the household changes the capital stock, it has to incur a cost in terms of foregone real income. Achieving smooth consumption is thus costly. The simplest form of capital adjustment costs is a quadratic cost function

$$
-\frac{\kappa}{2}\left(k_{t+1}-k_{t}\right)^{2}, \quad \kappa \geq 0
$$

In steady state, the adjustment cost is equal to zero. Further, as the adjustment cost is quadratic, it does not affect the resource constraint of the economy in a log-linear approximation of the model around a steady state. The Euler equation for capital now becomes

$$
1=\beta E_{t}\left[\frac{c_{t}}{c_{t+1}}\left(\frac{r_{t+1}-\delta}{q_{t}}+\frac{q_{t+1}}{q_{t}}\right)\right]
$$

where $q_{t} \equiv 1+\kappa\left(k_{t+1}-k_{t}\right)$ is Tobin's q, the price of capital in terms of current consumption. Notice that for $\kappa=0$, the Euler equation collapses to the Euler equation in the version without adjustment costs. The expression in the round brackets has an interpretation as a sum of a dividend yield and a capital gain. Denote the capital gain by $G_{t+1} \equiv q_{t+1} / q_{t}$.

The log-linearized system becomes

$$
\begin{gathered}
-\widehat{c}_{t}=-E_{t} \widehat{c}_{t+1}+\nu \pi_{t}-E_{t} \pi_{t+1}+\xi_{t} \\
-\widehat{c}_{t}=-E_{t} \widehat{c}_{t+1}+E_{t} \widehat{G}_{t+1}+r E_{t}\left(\widehat{c}_{t+1}+\frac{1+\eta}{1-\alpha} \widehat{y}_{t+1}-\frac{1+\alpha \eta}{1-\alpha} \widehat{k}_{t+1}\right) \\
\pi_{t}=\Psi\left[\frac{\eta+\alpha}{1-\alpha} \widehat{y}_{t}-\frac{\alpha(1+\eta)}{1-\alpha} \widehat{k}_{t}+\widehat{c}_{t}\right]+\beta E_{t} \pi_{t+1} \\
\widehat{y}_{t}=\frac{c}{y} \widehat{c}_{t}+\frac{k}{y} \widehat{k}_{t+1}-(1-\delta) \frac{k}{y} \widehat{k}_{t}
\end{gathered}
$$

where $\widehat{G}_{t+1}=\widehat{q}_{t+1}-\widehat{q}_{t}=\bar{\kappa}\left(\widehat{k}_{t+2}-\widehat{k}_{t+1}\right)-\bar{\kappa}\left(\widehat{k}_{t+1}-\widehat{k}_{t}\right)$ is a percentage deviation of capital gains from steady state and $\bar{\kappa} \equiv \kappa k$. Only equation (36) in the above system is different, 
compared with the system of the previous subsection. Of course, it coincides with equation (31) if $\kappa=0$. Combining equations (35) and (36), the ex-ante real interest rate can be written as the sum of capital gains and expected dividend yield

$$
\begin{aligned}
\widehat{R}_{t} & \equiv i_{t}-E_{t} \pi_{t+1} \\
& =\nu \pi_{t}+\xi_{t}-E_{t} \pi_{t+1} \\
& =E_{t} \widehat{G}_{t+1}+r E_{t}\left(\widehat{c}_{t+1}+\frac{1+\eta}{1-\alpha} \widehat{y}_{t+1}-\frac{1+\alpha \eta}{1-\alpha} \widehat{k}_{t+1}\right) .
\end{aligned}
$$

The exposition proceeds, as before, under the simplifying assumption that $r \approx 0$. Under this assumption, the dividend term in equations (36) and (39) drops out. Now, however, the capital gains term in equation (36) does not allow us to conclude that $\widehat{c}_{t}=E_{t} \widehat{c}_{t+1}=0$. Capital adjustment costs prevent perfect consumption smoothing, resulting in $\widehat{c}_{t} \neq E_{t} \widehat{c}_{t+1} \neq$ 0. Any drop in output dictated by inflation dynamics and the NKPC has to be, at least partially, accommodated by a drop in consumption. The higher is $\kappa$, the more any given change in the capital stock affects adjustment costs and capital gains and thus the expected growth rate of consumption. As a result, the higher is $\kappa$ the more any given change in output is accounted for by a change in consumption, rather than investment. Increasing $\kappa$ thus brings the response of consumption closer to the response of output and thus closer to the response of consumption in the version without capital; i.e., consumption falls on impact and converges back to steady state from below. As a result, $\widehat{R}_{t}=E_{t} \widehat{c}_{t+1}-\widehat{c}_{t}>0$. By bringing consumption closer to the basic model, capital adjustment costs also bring the response of inflation closer to the basic model. From (35), $\pi_{t}=\nu^{-1}\left(-\xi_{t}+E_{t} \pi_{t+1}+E_{t} \widehat{c}_{t+1}-\widehat{c}_{t}\right)$. This equation has the same form as equation (12) and the response of consumption is similar to that in the basic model.

The model can again be solved by the method of undetermined coefficients, guessing $\widehat{c}_{t}$, $\pi_{t}, \widehat{y}_{t}$, and $\widehat{k}_{t+1}$ as linear functions of $\widehat{k}_{t}$ and $\xi_{t}$. Relative to the system of restrictions in the model without adjustment costs, only the restrictions resulting from equation (36) are 
different. These are contained in the Appendix.

Figures $7-9$ show the responses of the model under $\kappa \in\{0.1,0.2,0.5\}$. The rest of the parameterization is as usual; in particular, $\theta=0.7$ and $\rho=0.5$. Observe that as $\kappa$ increases, the model starts to produce responses consistent with the real rate channel. Specifically, at $\kappa=0.1$ the model still suffers from producing a decline in the nominal interest rate and only a gradual increase in the ex-ante real rate. At $\kappa=0.2$, the ex-ante real rate increases on impact, but the nominal interest rate still falls. At $\kappa=0.5$, finally, both the ex-ante real rate and the nominal interest rate increase on impact. Throughout these experiments, the increase in the ex-ante real rate occurs due to expected capital gains.

Sufficiently high capital adjustment costs thus make the model consistent with the real rate channel. This consistency, however, is only observational. Capital adjustment costs in this model work in the same way as in asset-pricing business cycle models (e.g., Jermann, 1998; Tallarini, 2000). They prevent consumption smoothing. Here, consumers want to smooth consumption when income declines, as producers cut output in the face of a drop in inflation, as dictated by the NKPC. To prevent consumption smoothing in equilibrium, expected capital gains have to be sufficiently high. As a result, through the no-arbitrage principle, the ex-ante real interest rate - the real yield on a one-period bond-also has to be high. This outcome, however, while consistent with the real rate channel, is a byproduct of the decline in output, not its cause. In fact, as the real rate starts to increase with higher adjustment costs, the drop in output becomes smaller (compare Figure 7 with Figure 9). To demonstrate further that the real effects of monetary policy do not transmit through the real rate channel, we contrast Figure 9, which is observationally consistent with the real rate channel, with Figure 10. Figure 10 plots again the responses for $\kappa=0.5$, but under shock persistence $\rho=0.85$, instead of $\rho=0.5$. Now both inflation and the nominal interest rate decline, the ex-ante real interest rate also declines (on impact), yet output falls on impact as much as in Figure 9. Furthermore, the decline in output is much more persistent. The cumulative real effects are in fact larger. 


\section{Conclusion}

How does monetary policy affect inflation and output in the economy? A widely accepted view is that through its effect on the ex-ante real interest rate. In this paradigm, a common justification for the transmission from the nominal interest rate, the policy instrument, to the real interest rate, a price that ultimately affects decisions of the private sector, rests on nominal price rigidities. Introducing this channel into a modern dynamic stochastic general equilibrium environment was one of the motivations for the development of NewKeynesian models. These models, both in their basic and extended (medium-scale DSGE) forms are routinely used at central banks around the world to guide monetary policy. This paper scrutinizes the transmission mechanism in New-Keynesian models and argues that the presence of capital is important for understanding of how the transmission mechanism in these models works. Capital and investment are integral parts of real business cycle models, as well as the medium-scale New-Keynesian DSGE models. These models, however, contain many other features that, while helpful in matching the data, obscure the working of the transmission mechanism.

We demonstrate that, in general, the transmission mechanism in New-Keynesian models does not operate through the real rate channel. Instead, as a first pass, inflation is determined by Fisherian principles, through current and expected future monetary policy shocks, while output is then pinned down through Keynesian principles, the New-Keynesian Phillips curve. The real rate largely only reflects the desire and ability of households to smooth consumption in response to movements in output (income). A decline, increase, or no change in the ex-ante real interest rate is consistent with declines in output and inflation in response to a positive monetary policy shock. High enough capital adjustment costs make the model appear as if it operated through the real rate channel - the ex-ante real interest rate has to adjust so as to prevent consumption smoothing in equilibrium; a decline in output therefore coincides with an increase in the real rate. While observationally equivalent to the real rate channel, this is not how monetary policy, in general, transmits in New-Keynesian models. The critique 
applies equally to the basic framework without capital, which is a special case of the model with capital when capital adjustment costs are infinite.

The policy implication of our analysis is that (i) either monetary policy in actual economies does transmit through the real rate channel, but then the New-Keynesian model, at least in its common form, is not suitable for its analysis or (ii) the New-Keynesian model-for its micro-foundations of the price-setting behavior and internal consistency - is a useful description of actual economies, but then policy makers relying on this framework need to rethink the way monetary policy transmits into inflation and real activity. This paper outlined a simple approximate way how to think about the transmission mechanism.

\section{Appendix}

This Appendix contains results for the basic model under forward- and backward-looking Taylor rules, and the system that determines the equilibrium coefficients in the version with capital, both without and with capital adjustment costs.

\section{A.1. Forward-looking Taylor rule}

The monetary policy rule is $\widehat{i}_{t}=\nu E_{t} \pi_{t+1}+\xi_{t}$. Under this rule, the equilibrium is characterized by

$$
\begin{gathered}
-\widehat{y}_{t}=-E_{t} \widehat{y}_{t+1}+\nu E_{t} \pi_{t+1}+\xi_{t}-E_{t} \pi_{t+1}, \\
\pi_{t}=\Omega \widehat{y}_{t}+\beta E_{t} \pi_{t+1} .
\end{gathered}
$$

Guessing $y_{t}=a \xi_{t}$ and $\pi_{t}=b \xi_{t}$, yields

$$
b=-\frac{1}{(1-\rho) \frac{1-\beta \rho}{\Omega}+(\nu-1) \rho}<0,
$$

which differs only slightly from the solution for the contemporaneous Taylor rule by the second term in the denominator: $(\nu-1) \rho$ in the case of the forward-looking rule vs $(\nu-\rho)$ 
in the case of the contemporaneous rule.

\section{A.2. Backward-looking Taylor rule}

The monetary policy rule is $\widehat{i}_{t}=\nu \pi_{t-1}+\xi_{t}$. Under this rule, the equilibrium is characterized by

$$
\begin{gathered}
-\widehat{y}_{t}=-E_{t} \widehat{y}_{t+1}+\nu \pi_{t-1}+\xi_{t}-E_{t} \pi_{t+1}, \\
\pi_{t}=\Omega \widehat{y}_{t}+\beta E_{t} \pi_{t+1} .
\end{gathered}
$$

In this version of the model, there are two state variables: $\xi_{t}$ and $\pi_{t-1}$. Suppose that equilibrium output and the inflation rate are linear functions of the state

$$
y_{t}=a_{0} \pi_{t-1}+a_{1} \xi_{t} \quad \text { and } \quad \pi_{t}=b_{0} \pi_{t-1}+b_{1} \xi_{t}
$$

Using again the method of undetermined coefficients yields the following system of four equations in four unknowns

$$
\begin{gathered}
-a_{0}=-a_{0} b_{0}+\nu-b_{0}^{2}, \\
-a_{1}=-a_{0} b_{1}-a_{1} \rho+1-b_{0} b_{1}-b_{1} \rho \\
b_{0}=\Omega a_{0}+\beta b_{0}^{2} \\
b_{1}=\Omega a_{1}+\beta b_{0} b_{1}+\beta b_{1} \rho .
\end{gathered}
$$

This system has a recursive structure: the first and third equations determine $a_{0}$ and $b_{0}$, independently of $a_{1}$ and $b_{1}$. Combining these two equations yields a third-order polynomial

$$
\beta b_{0}^{3}+(1+\beta+\Omega) b_{0}^{2}+b_{0}+\Omega \nu=0,
$$

which has up to three distinct roots. For stability, we require either a unique root $\left|b_{0}\right|<1$ or one root less than one in absolute value, to load on past inflation, and two roots greater 
than one in absolute value, to eliminate bubble terms. Once $b_{0}$ is determined, the other coefficients are determined uniquely as

$$
a_{0}=\frac{1}{\Omega}\left(b_{0}-\beta b_{0}^{2}\right)
$$

and

$$
\left[\begin{array}{l}
a_{1} \\
b_{1}
\end{array}\right]=\left[\begin{array}{cc}
1-\rho & -\left(a_{0}+b_{0}+\rho\right) \\
-\Omega & \left(1-\beta b_{0}-\beta \rho\right)
\end{array}\right]^{-1}\left[\begin{array}{c}
-1 \\
0
\end{array}\right] .
$$

Notice that neither $b_{0}$ nor $a_{0}$ depend on the persistence of the shock. Thus, the higher the persistence of the shock, the more are the dynamics of the endogenous variables governed by the exogenous shock and the less by past inflation.

For the baseline parameterization $\beta=0.99, \eta=1, \nu=1.5, \theta=0.7$ (and $\rho=0.5$ ), the polynomial has a unique root, equal to -0.1478. Figure A.1 compares the impulse-responses under the backward-looking Taylor rule with those under the contemporaneous Taylor rule. The differences are small.

\section{A.3. Undetermined coefficients of the model with capital}

The equilibrium functions take the form: $\widehat{c}_{t}=a_{0} \widehat{k}_{t}+a_{1} \xi_{t}, \pi_{t}=b_{0} \widehat{k}_{t}+b_{1} \xi_{t}, \widehat{y}_{t}=d_{0} \widehat{k}_{t}+d_{1} \xi_{t}$,

and $\widehat{k}_{t+1}=f_{0} \widehat{k}_{t}+f_{1} \xi_{t}$. Using these functions in the system (30)-(33) and aligning terms yields a system of eight equations in eight unknowns, $a_{0}, a_{1}, b_{0}, b_{1}, d_{0}, d_{1}, f_{0}, f_{1}$. From equation (30) we get:

$$
\begin{gathered}
-a_{0}=-a_{0} f_{0}+\nu b_{0}-b_{0} f_{0} \\
-a_{1}=-a_{0} f_{1}-a_{1} \rho+\nu b_{1}-b_{0} f_{1}-b_{1} \rho+1 .
\end{gathered}
$$

From equation (31):

$$
-a_{0}=-(1-r) a_{0} f_{0}+\frac{r(1+\eta)}{1-\alpha} d_{0} f_{0}-\frac{r(1+\alpha \eta)}{1-\alpha} f_{0},
$$




$$
-a_{1}=-(1-r) a_{0} f_{1}-(1-r) a_{1} \rho+\frac{r(1+\eta)}{1-\alpha} d_{0} f_{1}+\frac{r(1+\eta)}{1-\alpha} d_{1} \rho-\frac{r(1+\alpha \eta)}{1-\alpha} f_{1} .
$$

From equation (32):

$$
\begin{gathered}
b_{0}=-\psi \frac{\eta+\alpha}{1-\alpha} d_{0}+\psi \frac{\alpha \eta+\alpha}{1-\alpha}-\psi a_{0}+\beta b_{0} f_{0}, \\
b_{1}=-\psi \frac{\eta+\alpha}{1-\alpha} d_{1}-\psi a_{1}+\beta b_{0} f_{1}+\beta b_{1} \rho .
\end{gathered}
$$

And from equation (33):

$$
\begin{gathered}
f_{0}=\frac{y}{k} d_{0}-\frac{c}{y} a_{0}+(1-\delta), \\
f_{1}=\frac{y}{k} d_{1}-\frac{c}{y} a_{1} .
\end{gathered}
$$

With capital adjustment costs, the second pair of equations in the this system becomes

$$
\begin{gathered}
-\bar{\kappa}-a_{0}+(1-r) a_{0} f_{0}-\frac{r(1+\eta)}{1-\alpha} d_{0} f_{0}+\frac{r(1+\alpha \eta)}{1-\alpha} f_{0}+2 \bar{\kappa} f_{0}-\bar{\kappa} f_{0}=0 \\
-a_{1}+(1-r) a_{0} f_{1}+(1-r) a_{1} \rho-\frac{r(1+\eta)}{1-\alpha} d_{0} f_{1}-\frac{r(1+\eta)}{1-\alpha} d_{1} \rho+\frac{r(1+\alpha \eta)}{1-\alpha} f_{1}+2 \bar{\kappa} f_{1}-\bar{\kappa} f_{0} f_{1}-\bar{\kappa} f_{1} \rho=0 .
\end{gathered}
$$




\section{References}

Bernanke, B. S., Gertler, M., 1995. Inside the black box: The credit channel of monetary transmission. Journal of Economic Perspectives 9, 27-48.

Bullard, J., 2015. Permazero as a possible medium-term outcome for the U.S. and the G-7. Speech at the FRB of Philadelphia Policy Forum, The New Normal for the U.S. Economy.

Bullard, J., Mitra, K., 2002. Learning about monetary policy rules. Journal of Monetary Economics 49, 1105-29.

Calvo, G., 1983. Staggered prices in a utility-maximizing framework. Journal of Monetary Economics 12, 38398.

Christiano, L. J., Eichenbaum, M., Evans, C. L., 2005. Nominal rigidities and the dynamic effects of a shock to monetary policy. Journal of Political Economy 113, 1-45.

Clarida, R., Galí, J., Gertler, M., 1999. The science of monetary policy: A new-Keynesian perspective. Journal of Economic Literature XXXVII, 1661-1707.

Cochrane, J., 2011. Determinacy and identification with Taylor rules. Journal of Political Economy 119, 565-615.

Cochrane, J., 2016. Do higher interest rates raise or lower inflation? Mimeo, Hoover Institution.

Galí, J., 2015. Monetary Policy, Inflation, and the Business Cycle: An Introduction to the New Keynesian Framework and Its Applications. Princeton University Press, Princeton.

Galí, J., Gertler, M., 2007. Macroeconomic modeling for monetary policy evaluation. Journal of Economic Perspectives 21, 25-45.

Ireland, P., 2015. The monetary transmission mechanism. In: Blume, L., Durlauf, S. (Eds.), The New Pelgrave Dictionary of Economics, 2nd Edition. Pelgrave Macmillan, Hampshire. 
Ireland, P. N., 2007. Changes in the Federal Reserve's inflation target: Causes and concequences. Journal of Money, Credit, and Banking 39, 1851-82.

Jermann, U. J., 1998. Asset pricing in production economies. Journal of Monetary Economics $41,257-75$.

Kocharlakota, N., 2016. Fragility of purely real macroeconomic models. NBER Working Paper 21866.

Kydland, F. E., Prescott, E. C., 1982. Time to build and aggregate fluctuations. Econometrica November, $1345-70$.

Linde, J., Smets, F., Wouters, R., 2015. Challenges for macro models used at central bank. Mimeo.

Long, J. B., Plosser, C. I., 1983. Real business cycles. Journal of Political Economy 91, 39-69.

McCandless, G., 2008. The ABCs of RBCs: An Introduction to Dynamic Macroeconomic Models. Harvard University Press, Cambridge.

Mishkin, F. S., 1996. The channels of monetary transmission: Lessons for monetary policy. NBER Working paper No. 5464.

Rotemberg, J., 1982. Monopolistic price adjustment and aggregate output. Review of Economic Studies 49, 517-31.

Smets, F., Wouters, R., 2003. An estimated dynamic stochastic general equilibrium model of the Euro Area. Journal of the European Economic Association 1, 1123-75.

Smets, F., Wouters, R., 2007. Shocks and frictions in U.S. business cycles: A Bayesian DSGE approach. American Economic Review 97, 586-606.

Tallarini, T. D., 2000. Risk-sensitive real business cycles. Journal of Monetary Economics $45,507-532$. 
Walsh, C. E., 2010. Monetary Theory and Policy, 3rd Edition. MIT Press, Cambridge.

Woodford, M., 2003. Interest and Prices: Foundations of a Theory of Monetary Policy. Princeton University Press. 
The EFFECT OF PRICE STICKINESS $(\theta)$
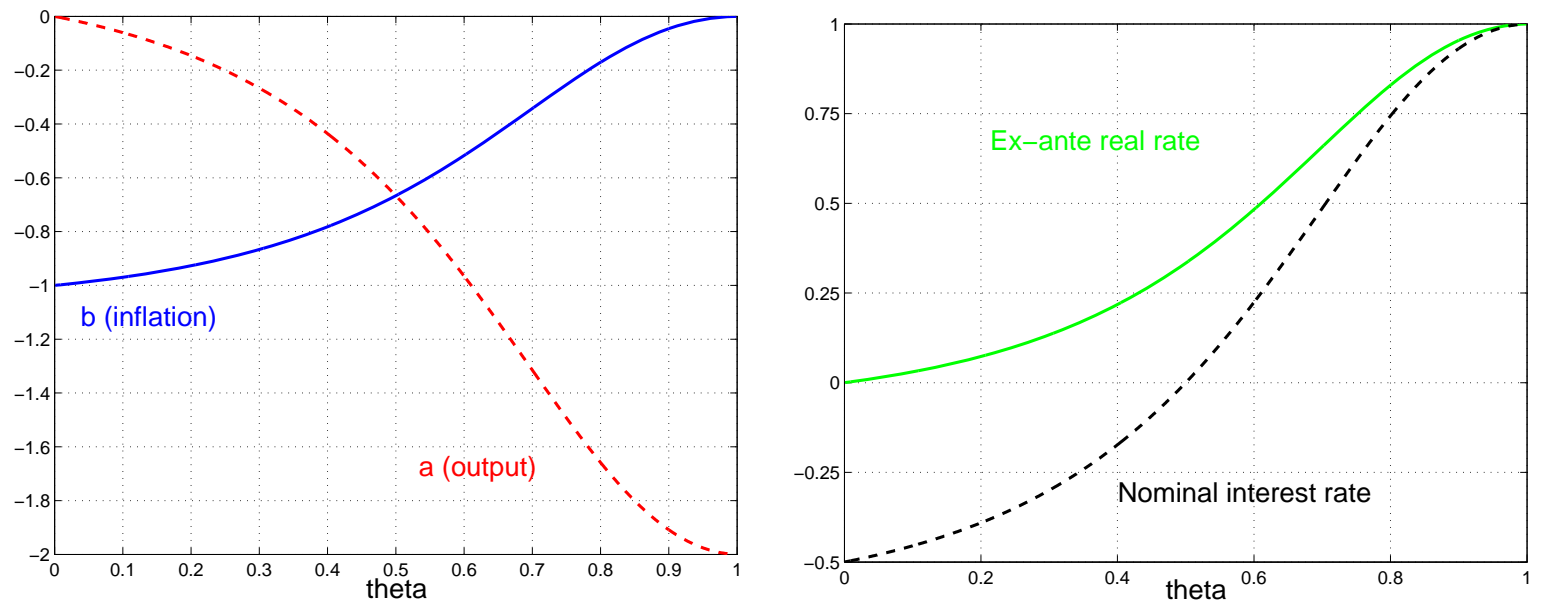

The EFFECT OF SHOCK PERSistence $(\rho)$
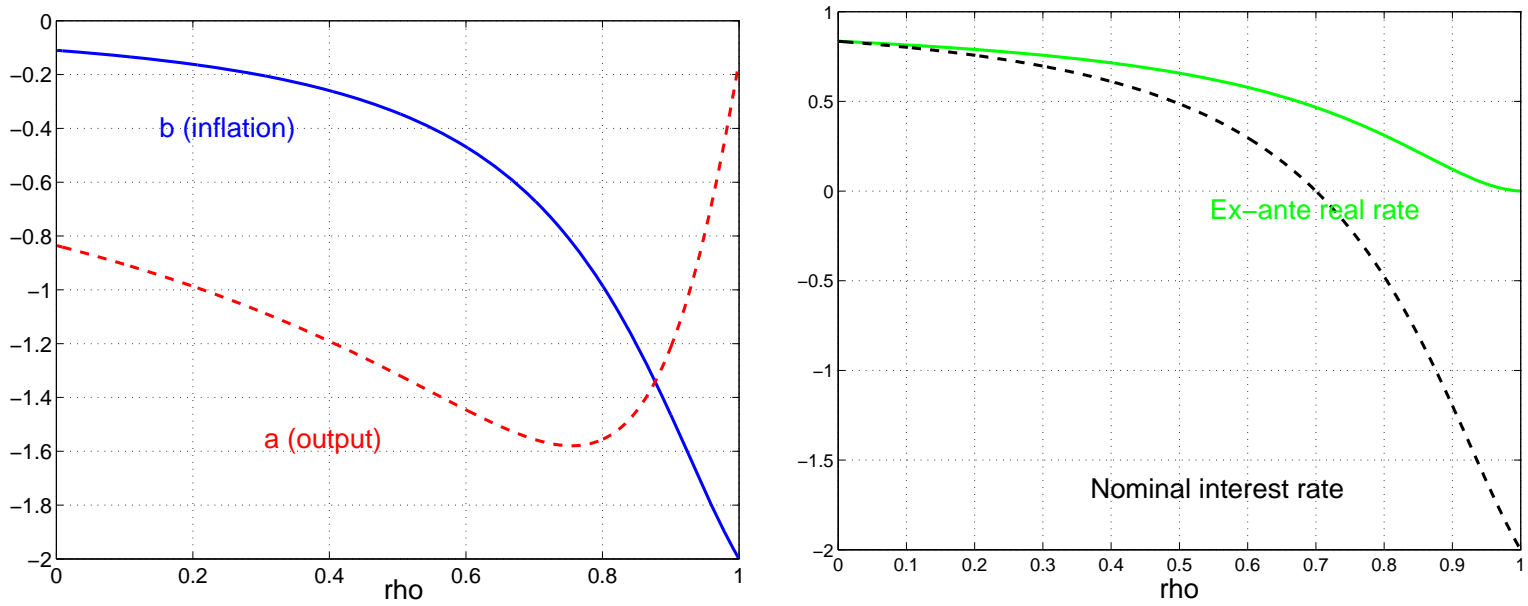

Figure 1: The effect of price stickiness (Calvo parameter $\theta$ ) and of the persistence of the monetary policy shock $(\rho)$ on the equilibrium coefficients (loading onto $\xi_{t}$ ) in the decision rule for output and the pricing functions for inflation, the nominal interest rate, and the ex-ante real rate. The baseline parameters are $\beta=0.99, \eta=1, \theta=0.7, \nu=1.5$, and $\rho=0.5$. 

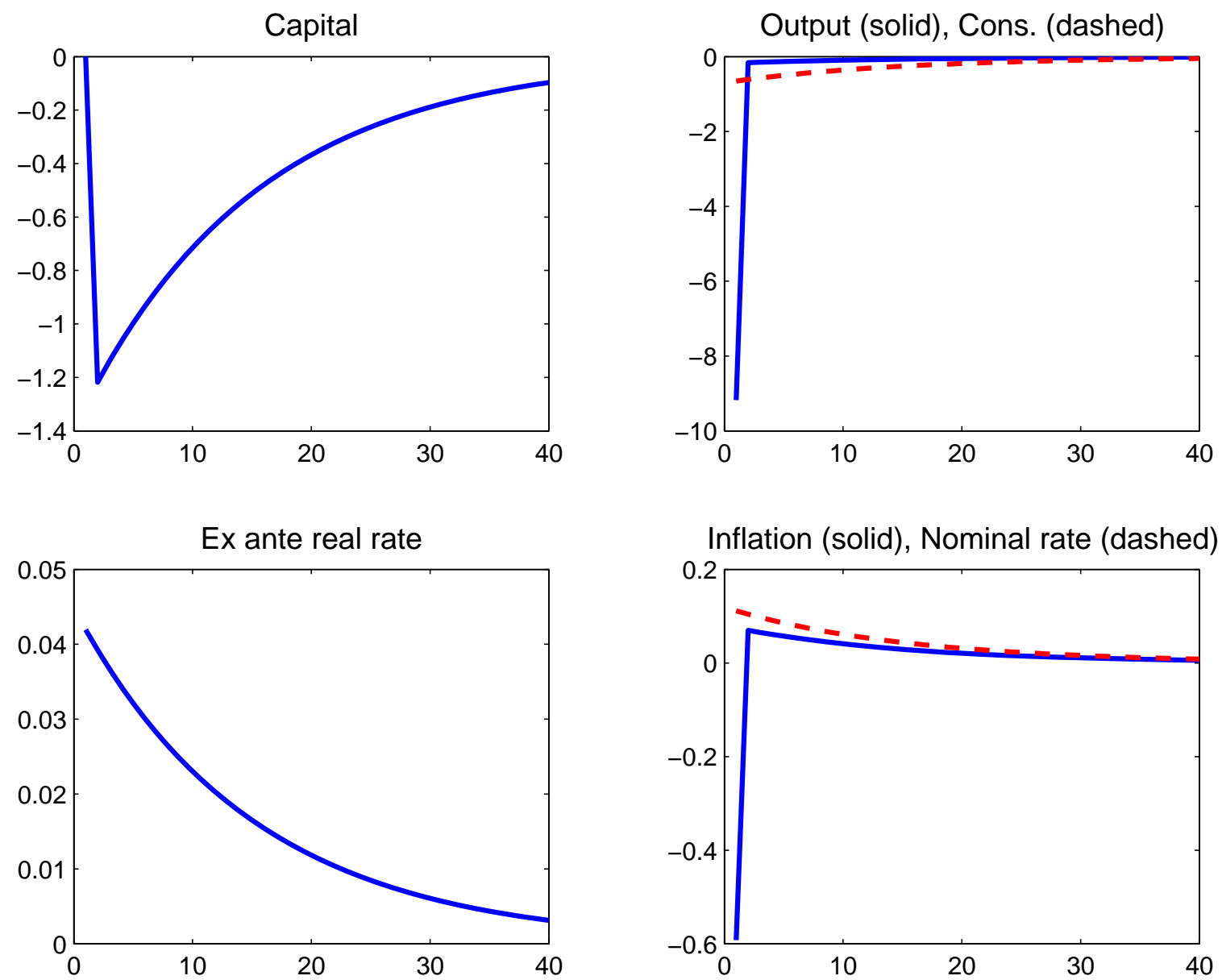

Figure 2: The model with capital, $\rho=0$. Responses to 1 percentage point increase in $\xi_{t}$. The remaining parameterization is: $\beta=0.99, \eta=1, \theta=0.7$, $\varepsilon=0.83, \nu=1.5, \alpha=0.3$, and $\delta=0.025$. 

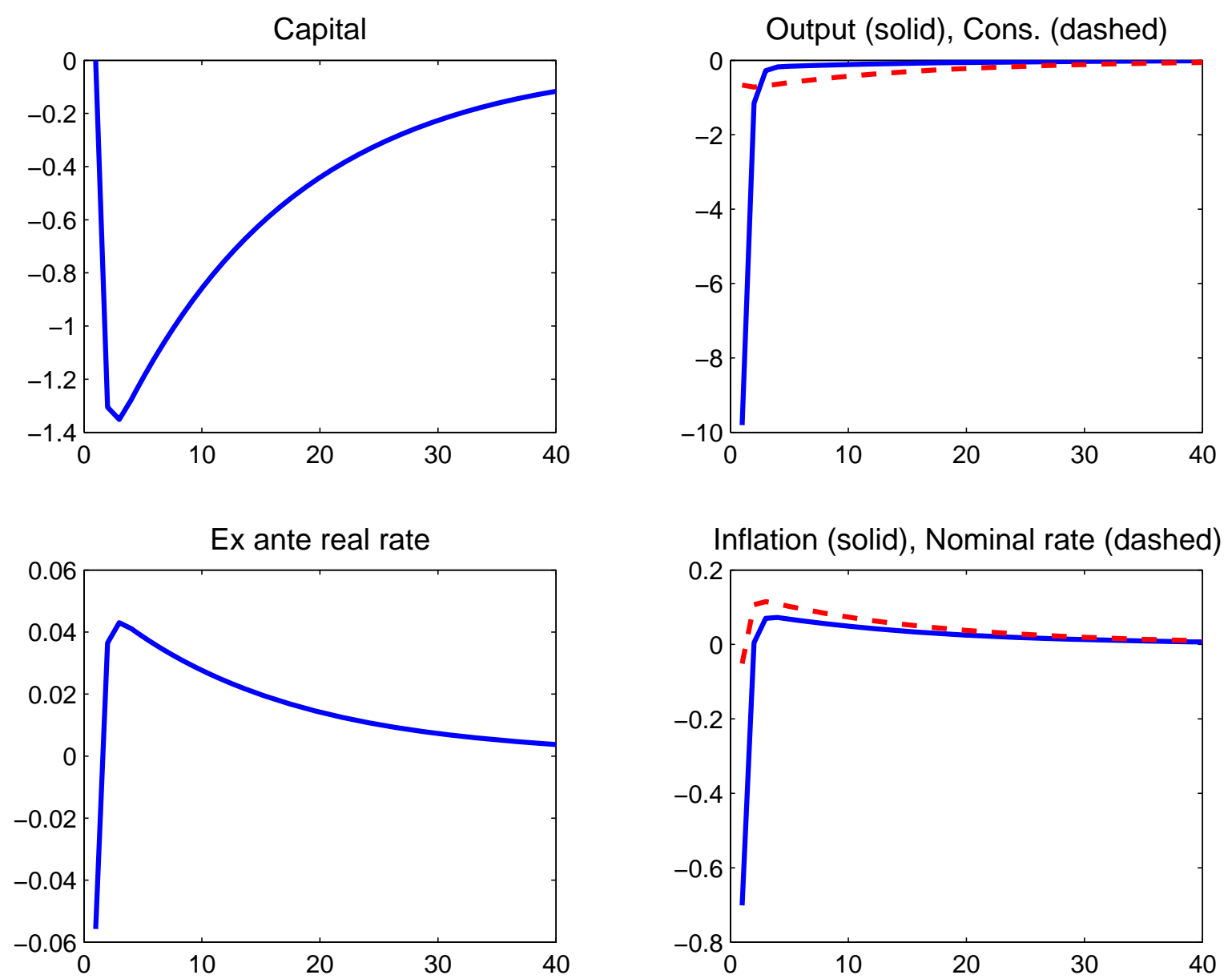

Figure 3: The model with capital, $\rho=0.1$. Responses to 1 percentage point increase in $\xi_{t}$. The remaining parameterization is: $\beta=0.99, \eta=1, \theta=0.7$, $\varepsilon=0.83, \nu=1.5, \alpha=0.3$, and $\delta=0.025$. 

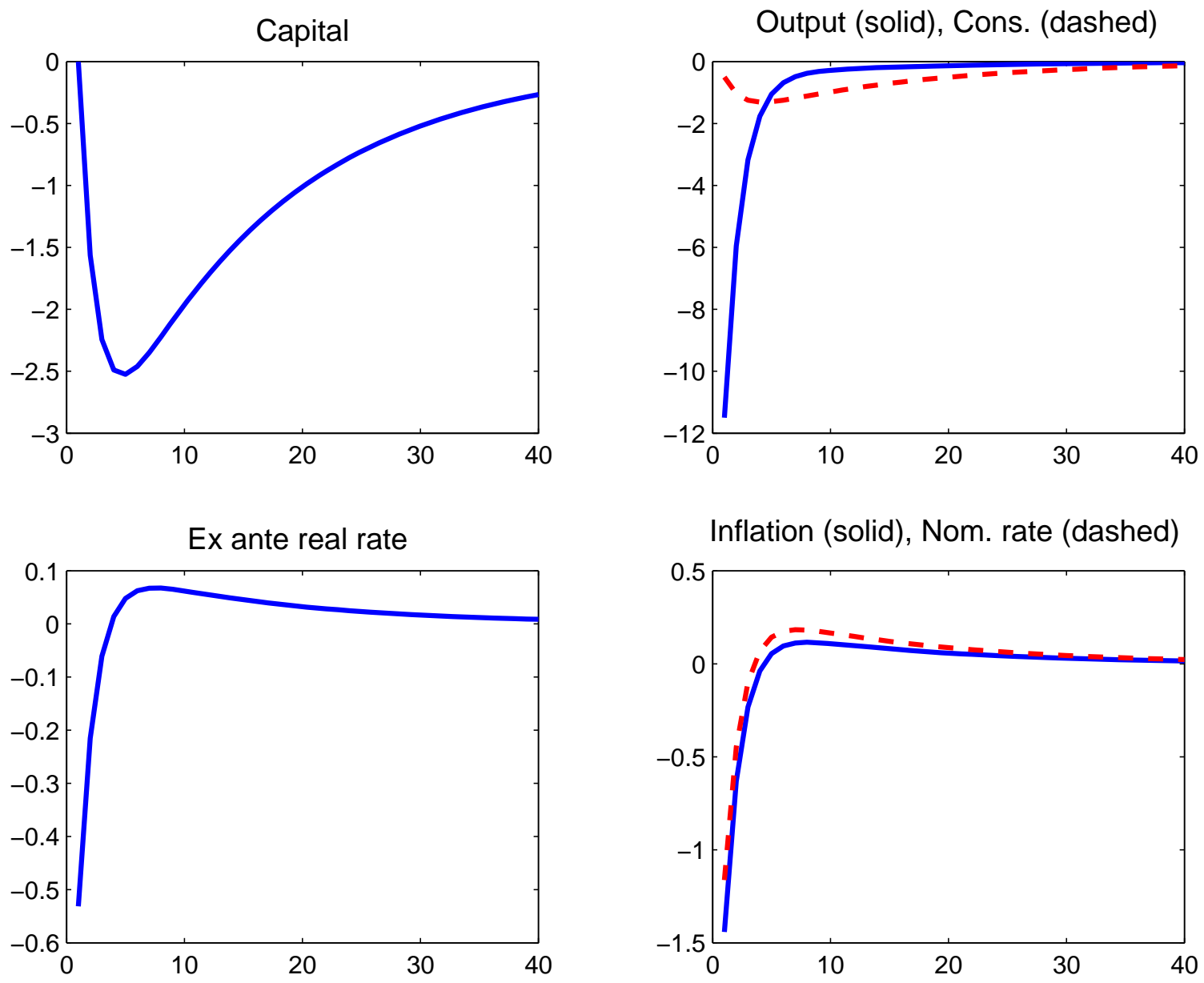

Figure 4: The model with capital, $\rho=0.5$. Responses to 1 percentage point increase in $\xi_{t}$. The remaining parameterization is: $\beta=0.99, \eta=1, \theta=0.7$, $\varepsilon=0.83, \nu=1.5, \alpha=0.3$, and $\delta=0.025$. 

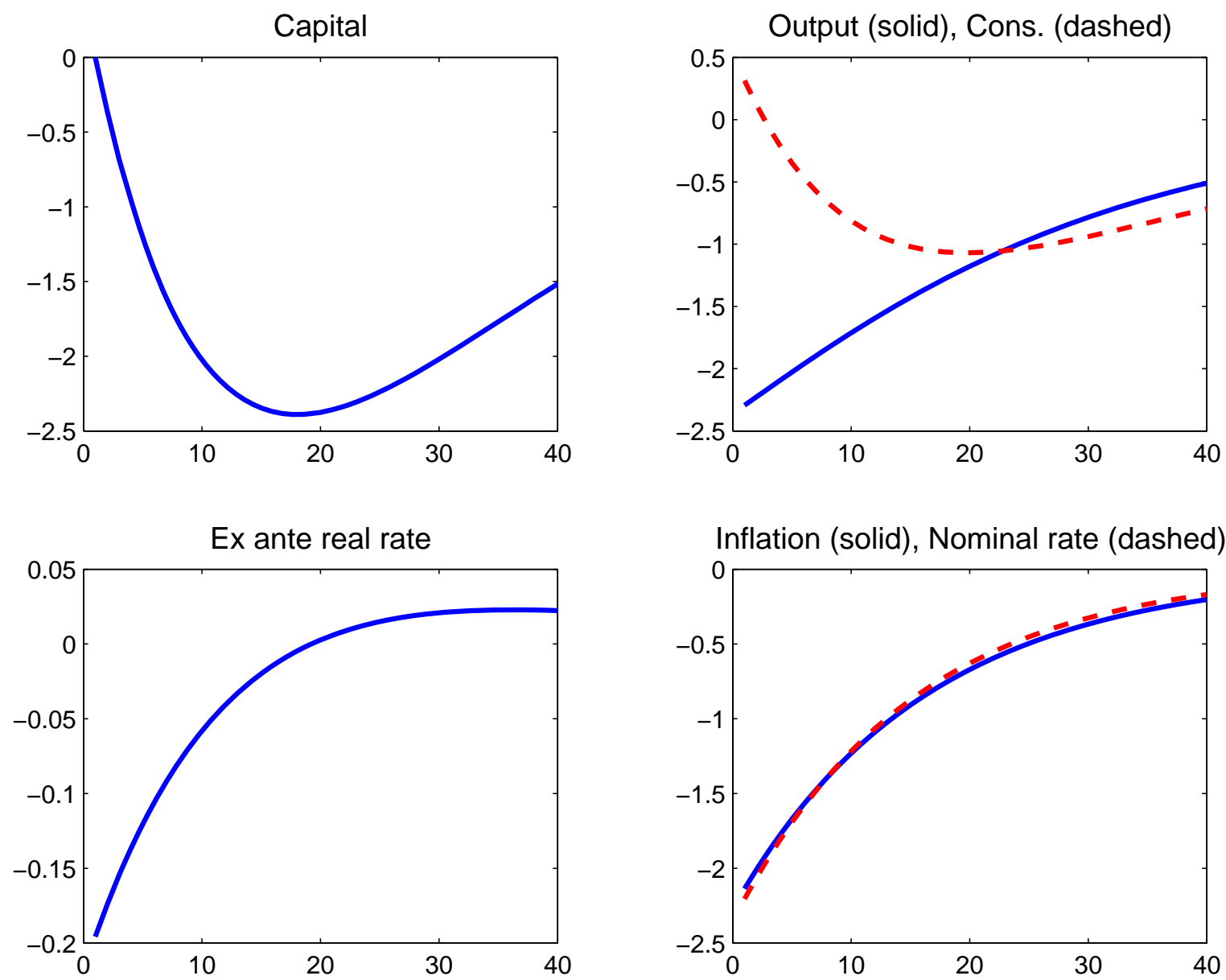

Figure 5: The model with capital, $\rho=0.95$. Responses to 1 percentage point increase in $\xi_{t}$. The remaining parameterization is: $\beta=0.99, \eta=1, \theta=0.7$, $\varepsilon=0.83, \nu=1.5, \alpha=0.3$, and $\delta=0.025$. 

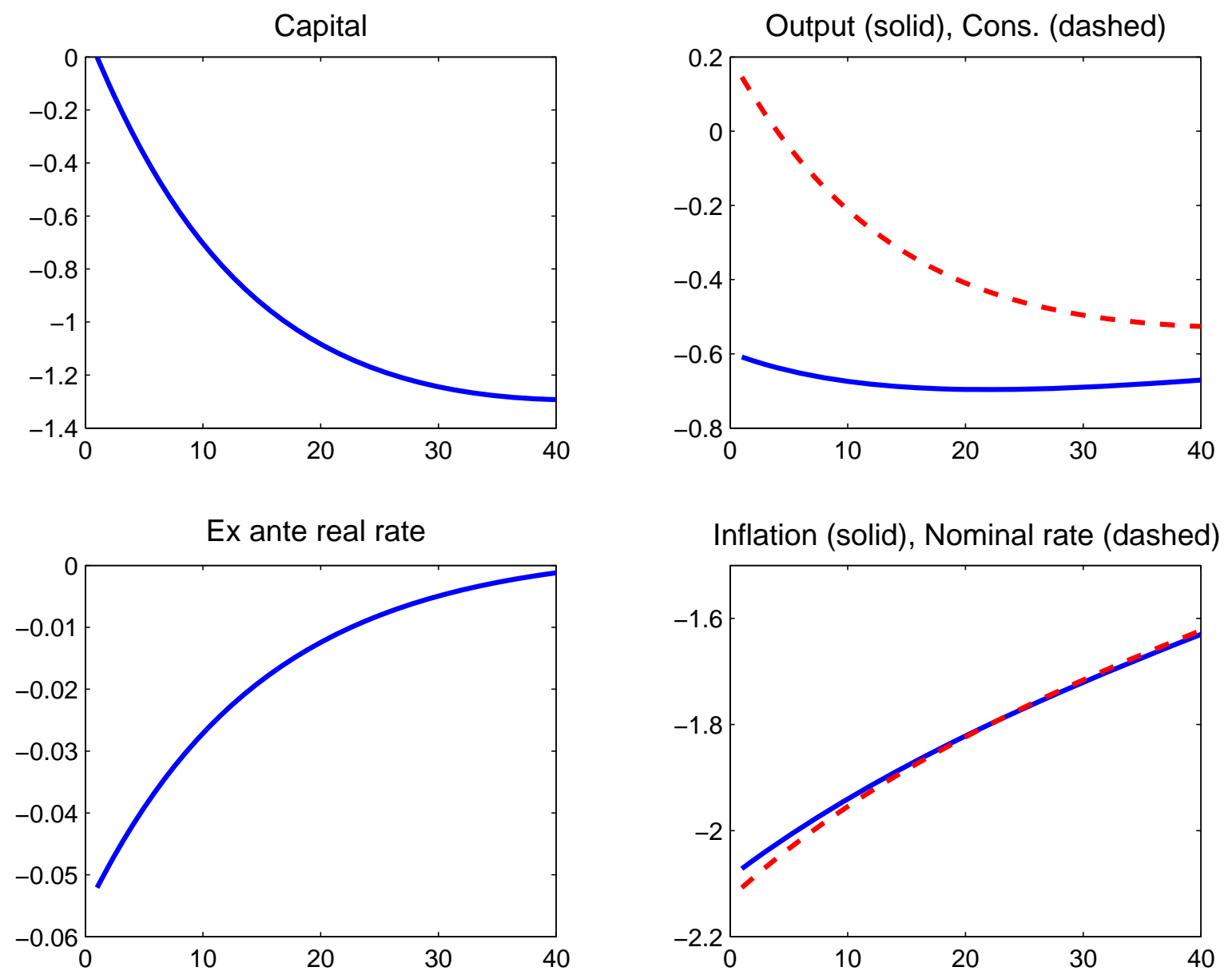

Figure 6: The model with capital, $\rho=0.995$. Responses to 1 percentage point increase in $\xi_{t}$. The remaining parameterization is: $\beta=0.99, \eta=1, \theta=0.7$, $\varepsilon=0.83, \nu=1.5, \alpha=0.3$, and $\delta=0.025$. 

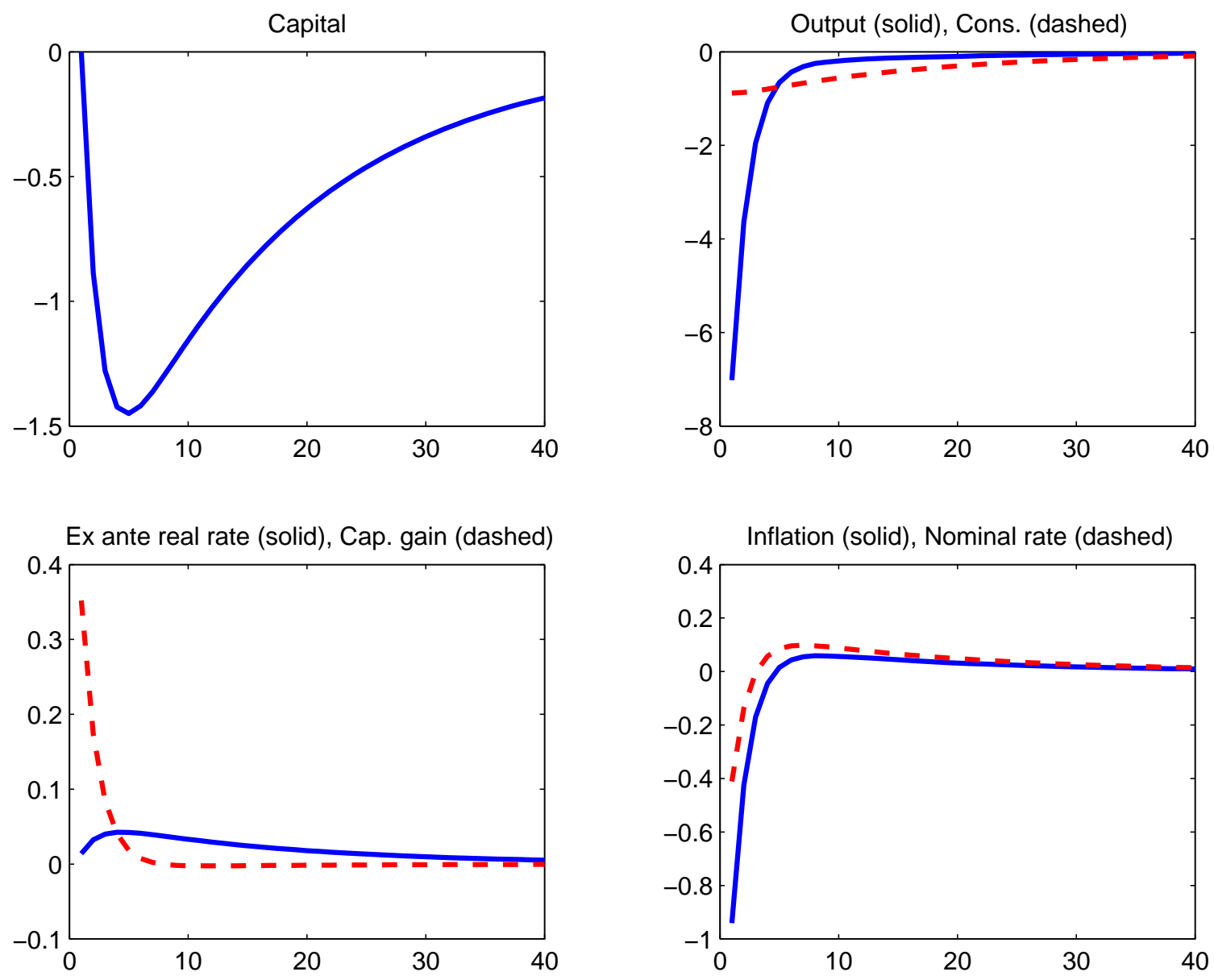

Figure 7: The model with capital adjustment costs, $\kappa=0.1$. Responses to 1 percentage point increase in $\xi_{t}$. The remaining parameterization is: $\beta=0.99$, $\eta=1, \theta=0.7, \varepsilon=0.83, \nu=1.5, \alpha=0.3, \delta=0.025$, and $\rho=0.5$. 

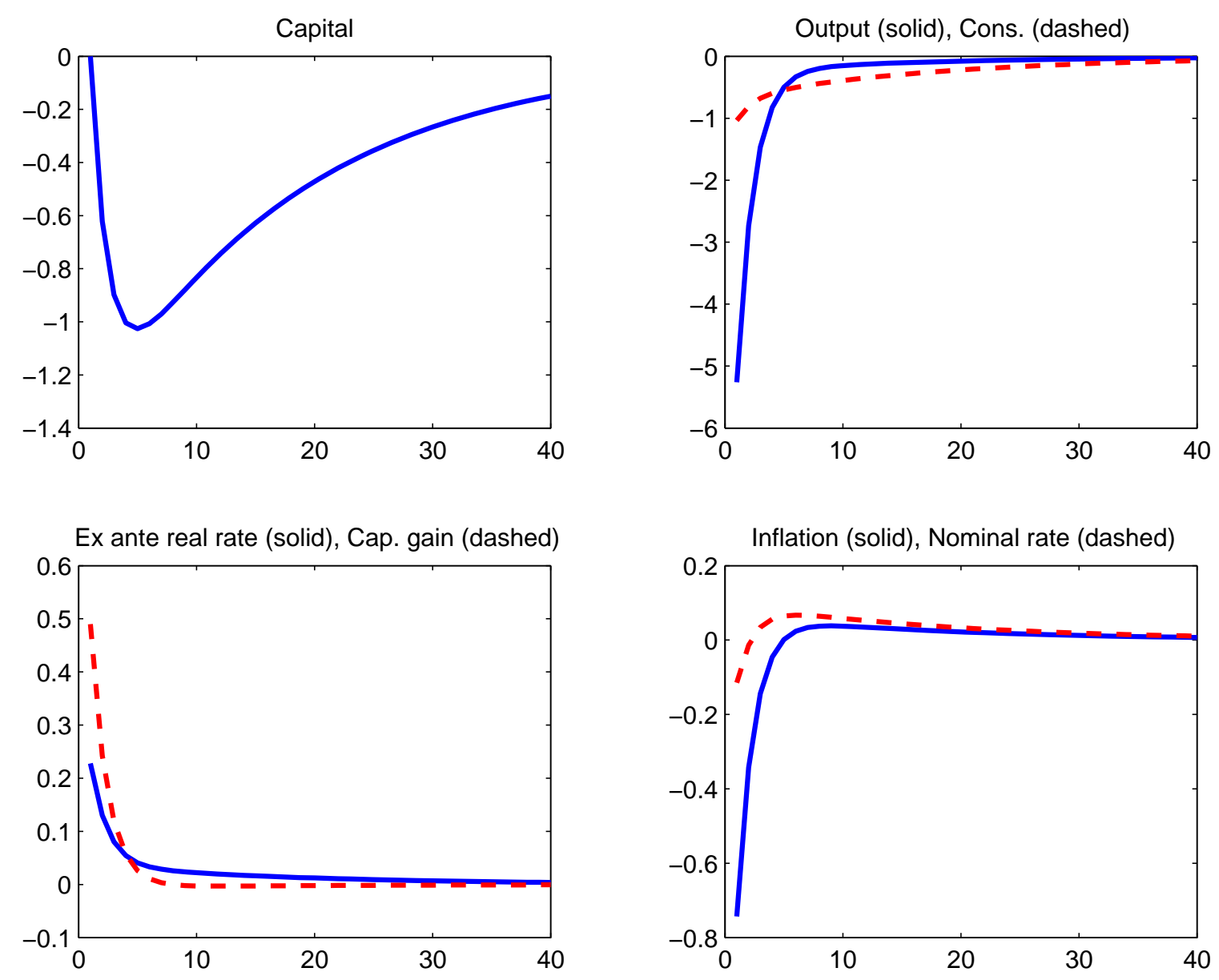

Figure 8: The model with capital adjustment costs, $\kappa=0.2$. Responses to 1 percentage point increase in $\xi_{t}$. The remaining parameterization is: $\beta=0.99$, $\eta=1, \theta=0.7, \varepsilon=0.83, \nu=1.5, \alpha=0.3, \delta=0.025$, and $\rho=0.5$. 

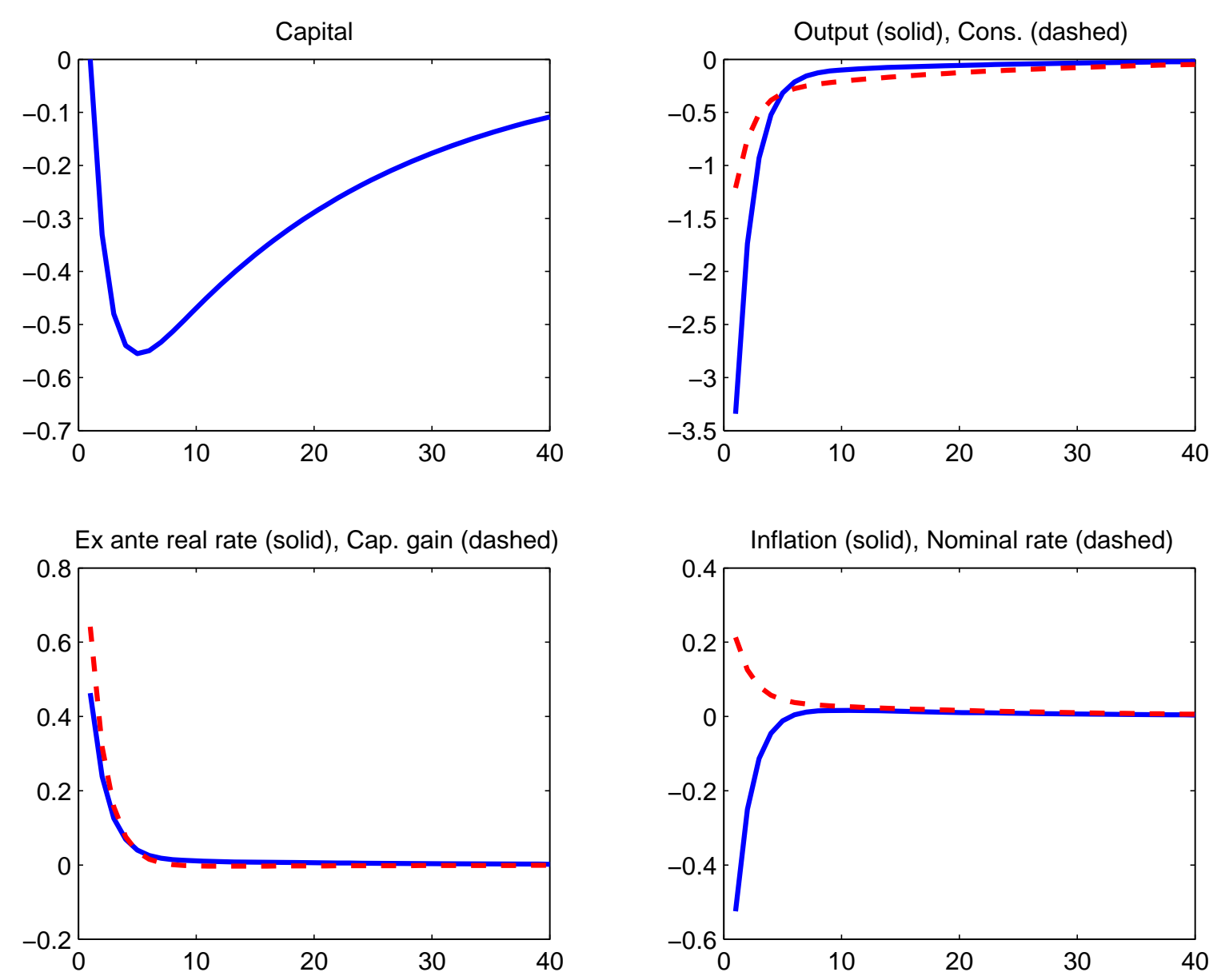

Figure 9: The model with capital adjustment costs, $\kappa=0.5$. Responses to 1 percentage point increase in $\xi_{t}$. The remaining parameterization is: $\beta=0.99$, $\eta=1, \theta=0.7, \varepsilon=0.83, \nu=1.5, \alpha=0.3, \delta=0.025$, and $\rho=0.5$. 

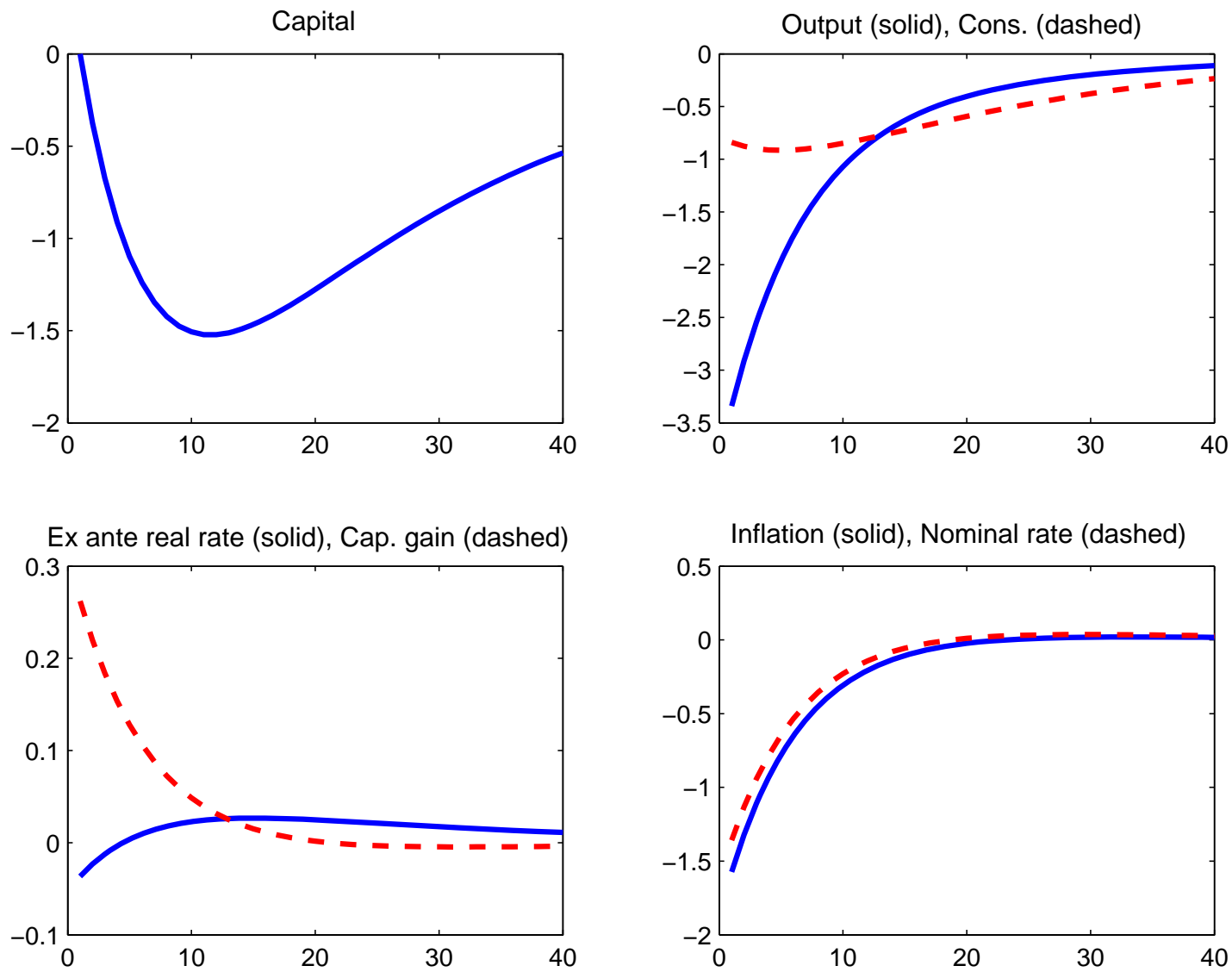

Figure 10: The model with capital adjustment costs, $\kappa=0.5$, but higher shock persistence, $\rho=0.85$. Responses to 1 percentage point increase in $\xi_{t}$. The remaining parameterization is: $\beta=0.99, \eta=1, \theta=0.7, \varepsilon=0.83$, $\nu=1.5, \alpha=0.3$, and $\delta=0.025$. 


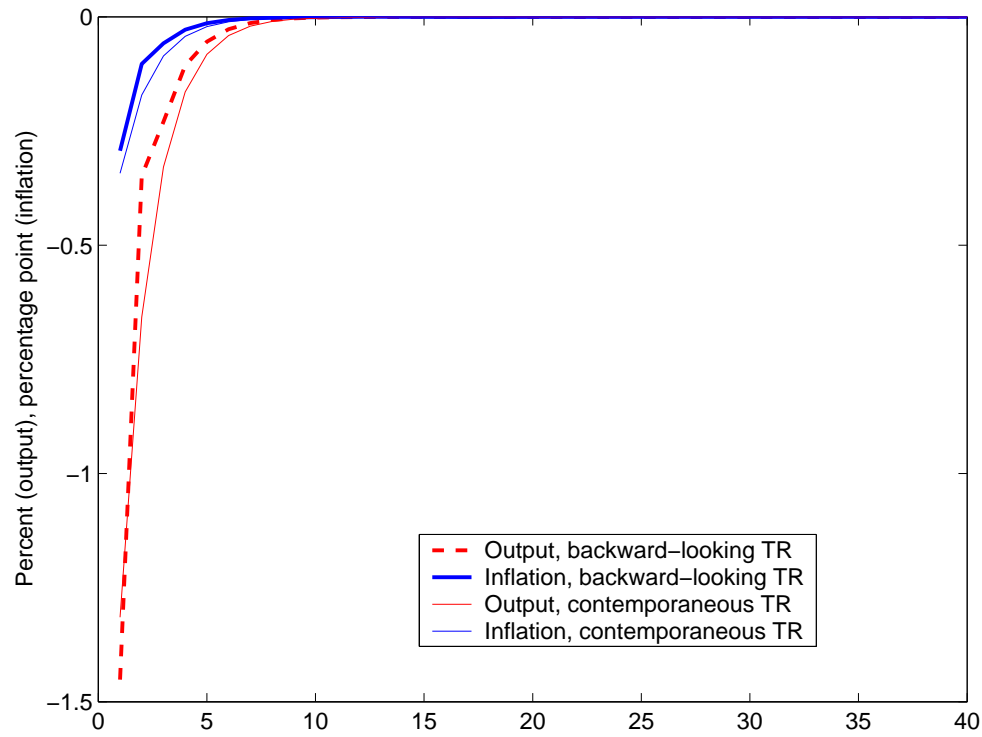

Fig. A.1. Backward-looking vs contemporaneous Taylor rule. Responses to a 1 percentage point increase in the monetary policy shock $\xi_{t}$. The parameterization is $\beta=0.99, \eta=1, \theta=0.7, \nu=1.5$, and $\rho=0.5$. 